\title{
Research Status of Evolution of Microstructure and Properties of Sn-Based Lead-Free Composite Solder Alloys
}

\author{
Shuai Li $\mathbb{D},{ }^{1,2}$ Xingxing Wang $\mathbb{D},{ }^{1,3}$ Zhongying Liu, ${ }^{1}$ Feng Mao, ${ }^{2}$ Yongtao Jiu, ${ }^{4}$ Jingyi Luo, ${ }^{4}$ \\ Linjian Shangguan, ${ }^{1}$ Xiangjie Jin, ${ }^{1}$ Gang Wu, ${ }^{1}$ Shuye Zhang, ${ }^{3}$ Peng He $\mathbb{D}^{3},{ }^{3}$ and Weimin Long $^{5}$ \\ ${ }^{1}$ School of Mechanical Engineering, North China University of Water Resources and Electric Power, Zhengzhou 450045, China \\ ${ }^{2}$ National Joint Engineering Research Center for Abrasion Control and Molding of Metal Materials, \& Henan Key Laboratory of \\ High-Temperature Structural and Functional Materials, Henan University of Science and Technology, Luoyang 471003, China \\ ${ }^{3}$ State Key Laboratory of Advanced Welding and Joining, Harbin Institute of Technology, Harbin 150001, China \\ ${ }^{4}$ Jinhua Jinzhong Welding Materials Co. Ltd., Jinhua 321016, China \\ ${ }^{5}$ State Key Laboratory of Advanced Brazing Filler Metals \& Technology, Zhengzhou Research Institute of Mechanical Engineering, \\ Zhengzhou 450001, China
}

Correspondence should be addressed to Xingxing Wang; paperwxx@126.com and Peng He; hithepeng@hit.edu.cn

Received 5 August 2020; Revised 13 November 2020; Accepted 24 November 2020; Published 14 December 2020

Academic Editor: Fengqiang Sun

Copyright ( 2020 Shuai Li et al. This is an open access article distributed under the Creative Commons Attribution License, which permits unrestricted use, distribution, and reproduction in any medium, provided the original work is properly cited.

\begin{abstract}
With the miniaturization of solder joints and deterioration of serving environment, much effort had been taken to improve the properties of Sn-based lead-free solders. And the fabrication of Sn-based lead-free composite solder alloys by the addition of nanoparticles is one of the effective ways to enhance the properties. In this paper, the recent research progress on the Sn-based lead-free composite solder alloys is reviewed by summarizing the relevant results in representative ones of $\mathrm{Sn}-\mathrm{Ag}-\mathrm{Cu}(\mathrm{SAC}), \mathrm{Sn}-\mathrm{Bi}$, and other multielement lead-free composite solder alloys. Specifically speaking, the effect of the added nanoparticles on the evolution of wettability, microstructure morphology, and mechanical properties of Sn-based lead-free composite solder alloys are summarized. It is hoped that this paper could supply some beneficial suggestions in developing the novel Sn-based lead-free composite solder alloys. Additionally, the existed issues and future development trends in the exploitation of new novel Sn-based lead-free composite solder alloys are proposed.
\end{abstract}

\section{Introduction}

In recent decades, the application of traditional $\mathrm{Sn}-\mathrm{Pb}$ binary alloy solder in electronic and electrical field has been prohibited gradually due to the toxic of lead $(\mathrm{Pb})$ element $[1,2] . \mathrm{Pb}$ is a heavy metal element that seriously endangers human health, especially the growth and intellectual development infants and young children. Consequently, much attention had been paid to explore novel lead-free solder alloys by the worldwide investigator. And a series of Sn-based lead-free solder alloys have been fabricated, which mainly consist of $\mathrm{Sn}-\mathrm{Ag}-\mathrm{Cu}$ (SAC), Sn-Bi, Sn-Zn, and Sn-Cu series of solder alloys [3]. However, the shortcomings of relative poor wettability, higher soldering temperature, coarsening of intermetallic compounds (IMCs), and unsatisfactory mechanical properties compared with $\mathrm{Sn}-\mathrm{Pb}$ solder have inhibited their popularization and application $[4,5]$. Furthermore, with the miniaturization of solder joints and deterioration of serving environment (radiation condition, corrosive environment, and drop impact), many measures had been taken to improve the properties of Sn-based lead-free solder alloys $[6,7]$. Consequently, trace amount of alloying elements ( $\mathrm{Ni}$ [8-10], Mn [11], Bi [12], Co [13, 14], Cr [15], Al [9], Sb [10], Fe [16], and rare earth (RE) $[17,18]$ ) is incorporated with Sn-based lead-free solder to enhance the comprehensive properties. Moreover, with the popularity and utilization of nanometer materials fabricating technology, the nanometer particles are doped with Sn-based lead-free solder to improve the comprehensive properties, such as nanometer oxide $\left(\mathrm{Al}_{2} \mathrm{O}_{3}\right.$ [19-21], $\mathrm{BaTiO}_{3}$ [22], $\mathrm{Y}_{2} \mathrm{O}_{3}$ [23], $\mathrm{TiO}_{2}$ [24-27], and 
TABLe 1: Typical type of addition in composite Sn-based lead-free solder [45].

\begin{tabular}{|c|c|c|c|c|}
\hline Type & Kinds of additions & Representative material & Advantage & Disadvantage \\
\hline \multirow{4}{*}{ Non-reactive } & Oxide & $\begin{array}{c}\mathrm{Al}_{2} \mathrm{O}_{3}[19-21], \mathrm{TiO}_{2}[24,25,27,50] \\
\mathrm{ZnO}[49,51-53], \\
\mathrm{ZrO}_{2}[28,29], \mathrm{Fe}_{2} \mathrm{O}_{3}[54,55], \mathrm{La}_{2} \mathrm{O}_{3}[56] \\
\mathrm{CeO}_{2}[57]\end{array}$ & \multirow{4}{*}{ Stabilization } & \multirow{4}{*}{ Worse retention rate } \\
\hline & Carbide & $\operatorname{TiC}[30], \mathrm{SiC}[31]$ & & \\
\hline & Carbon nanometer & $\begin{array}{l}\text { CNTs [35-37], graphene [38-40], } \\
\text { fullerenes [41-43] }\end{array}$ & & \\
\hline & Elementary substance & Diamond [58] & & \\
\hline \multirow[t]{2}{*}{ Reactive } & Metal & $\begin{array}{l}\text { Ni [8-10], Mn [11], Bi [12], Co }[13,14] \text {, } \\
\text { Cr [15], Al [9], } \\
\text { Sb [10], Fe [16], rare earth (RE) }[17,18]\end{array}$ & \multirow[t]{2}{*}{ Coarsening of IMC } & \multirow[t]{2}{*}{ Formation of IMC } \\
\hline & IMCs & $\mathrm{Cu}_{6} \mathrm{Sn}_{5}[32-34]$ & & \\
\hline \multirow{2}{*}{$\begin{array}{l}\text { Compound } \\
\text { type }\end{array}$} & Organic macromolecule & Epoxy $[59,60]$ & \multirow[b]{2}{*}{ Good retention rate } & \multirow{2}{*}{$\begin{array}{l}\text { High cost, } \\
\text { deterioration } \\
\text { of serve reliability }\end{array}$} \\
\hline & $\begin{array}{l}\text { Metal-plated carbon } \\
\text { nanometer }\end{array}$ & $\begin{array}{c}\text { Ag-decorated CNTs [35], Sn-decorate } \\
\text { CNTs [61] }\end{array}$ & & \\
\hline
\end{tabular}

$\left.\mathrm{ZrO}_{2}[28,29]\right)$, nanometer carbide ([30, 31]), nanometer IMC $\left(\mathrm{Cu}_{6} \mathrm{Sn}_{5}\right.$ [32-34]), and carbon-based nanometer materials (carbon nanotubes (CNTs) [35-37], graphene [38-40], and fullerenes [41-43]). Generally speaking, the addition of nanoparticles acts as reinforcing phase in the Sn-based lead-free composite solder alloys. Then, the reliability of composite solder joints improved under extreme conditions and the possible applications for Sn-based lead-free composite solder alloys mainly included the spacecraft in deep space at cryogenic temperatures and radiation conditions [44].

The investigations of Sn-based lead-free composite solder are still in the research stage. And the investigations on the properties of Sn-based composite solder alloys are isolated and the involved experiment results are sporadic, and even some conclusions are inconsistent. Therefore, it is necessary to summarize the investigation status on the performances of Sn-based lead-free composite solder in recent decades. The review is to summarize the influences of incorporating various nanometer particles on the performances (wettability, microstructure, and mechanical properties) of Sn-based lead-free composite solders in recent researches and then supply some suggestions in the future research work.

\section{Fundamentals of the Preparation}

2.1. Typical Addition. The typical additions in the Sn-based lead-free composite solders can be divided into three types, namely, compound type, nonreactive and reactive nanoparticles depending on whether the metallurgical reactions occurred between the added nanoparticles, and solder matrix during reflow cycle or aging, with the details as listed in Table 1 [45]. For the nonreactive additions, there is no metallurgical reaction between the incorporation and solder alloys. Consequently, no growth and coarsen phenomenon occurred during the reflow cycle and service process. However, it is difficult for the occurrence of reactive wetting between the additions and solder alloy. Consequently, the additions are always squeezed out due to interfacial energy during the reflux process. Then, the error between designed addition and actual existing content appeared. At present, the reactive additions are investigated extensively. For this type of additions, it is easy for the occurrence of metallurgical reaction between the additions and solder alloys. Then, the additions exist in the form of IMC in the solder joints. Nonetheless, the existed IMC formed between the additions and solder will become large during the period of service, then resulted in the deterioration of mechanical properties. Moreover, the novel additions, such as epoxy, fullerenes, and metal-plated CNTs, can be preserved in the form of bonding with the solder substrate, which has stable physical and chemical properties, and it is difficult to produce coarse growth during the period of service. However, the electrical properties of solders may be affected due to the poor thermal conductivity. Moreover, the cost to fabricate is a challenge for the novel incorporations due to complex preparation processes.

\subsection{Preparation and Experimental Method of Composite} Solder. At present, the fabrication methods of composite solder mainly consist of mechanical mixing and in situ synthesis. Chen et al. [46] fabricated the novel SAC305 added with Ni-plated graphene nanosheet lead-free composite solder by the method of powder metallurgy. In the experiment, the Ni-plated GNS are prepared by three steps: (1) dispersion of the GNS with ultrasonic, (2) activation and sensitization of GNS, and (3) Nickel plating by the method of electroless, as shown in Figure 1. Then, the SAC305 solder powders were uniform mixed with Ni-GNS nanosheets in a ball mill for $20 \mathrm{~h}$ with the speed of $180 \mathrm{r} / \mathrm{min}$. Then, the compacted solder billets are sintered under the condition of vacuum. Finally, the sintered solder alloys were rolled into solder foils with the thickness of around $200 \mu \mathrm{m}$. A similar fabrication method is also adopted by Khodabakhshi et al. [47], as shown in Figure 2. Shen et al. [48] fabricated the Sn-3.5Ag composite solders by the method of in situ synthesis. First, the solder ingot casting is prepared in vacuum furnace; then, the Sn3.5Ag composite solders is fabricated by rapid solidification. 


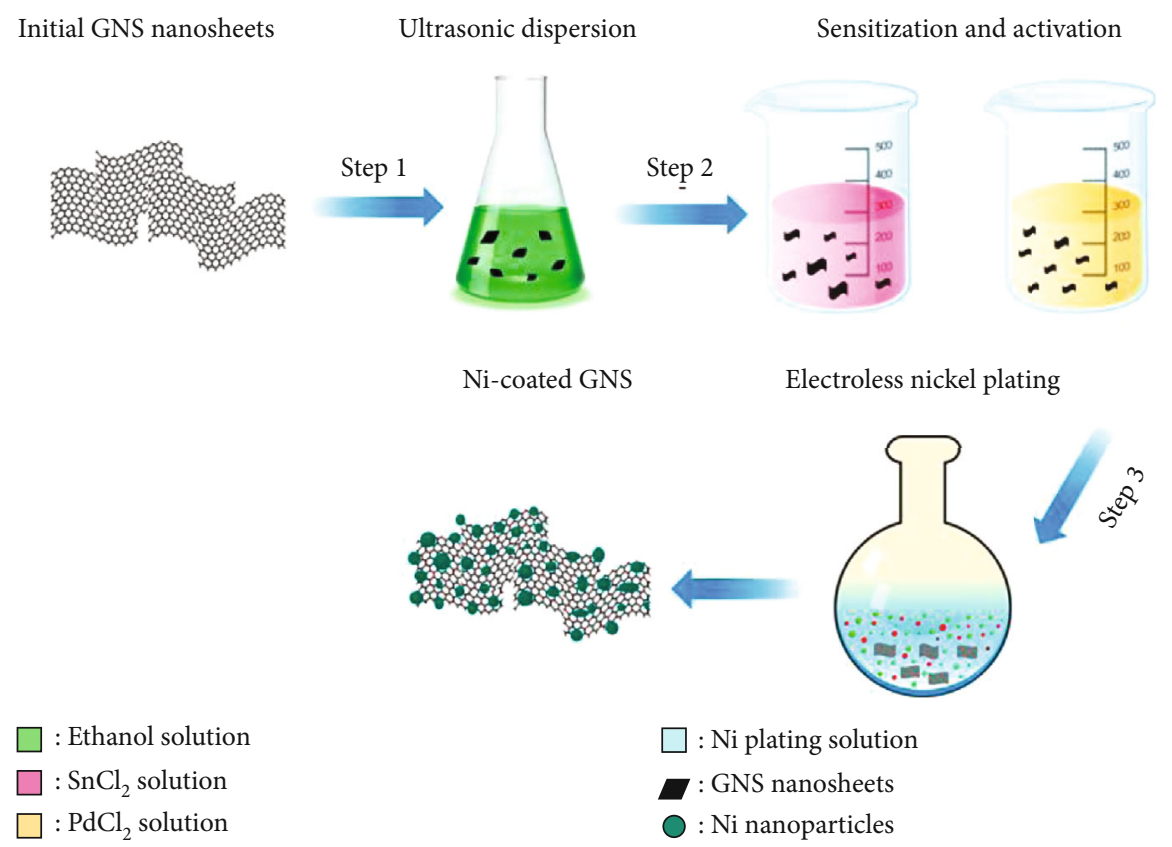

Figure 1: Schematic diagram of fabrication of Ni-decorated graphene nanosheets [46].

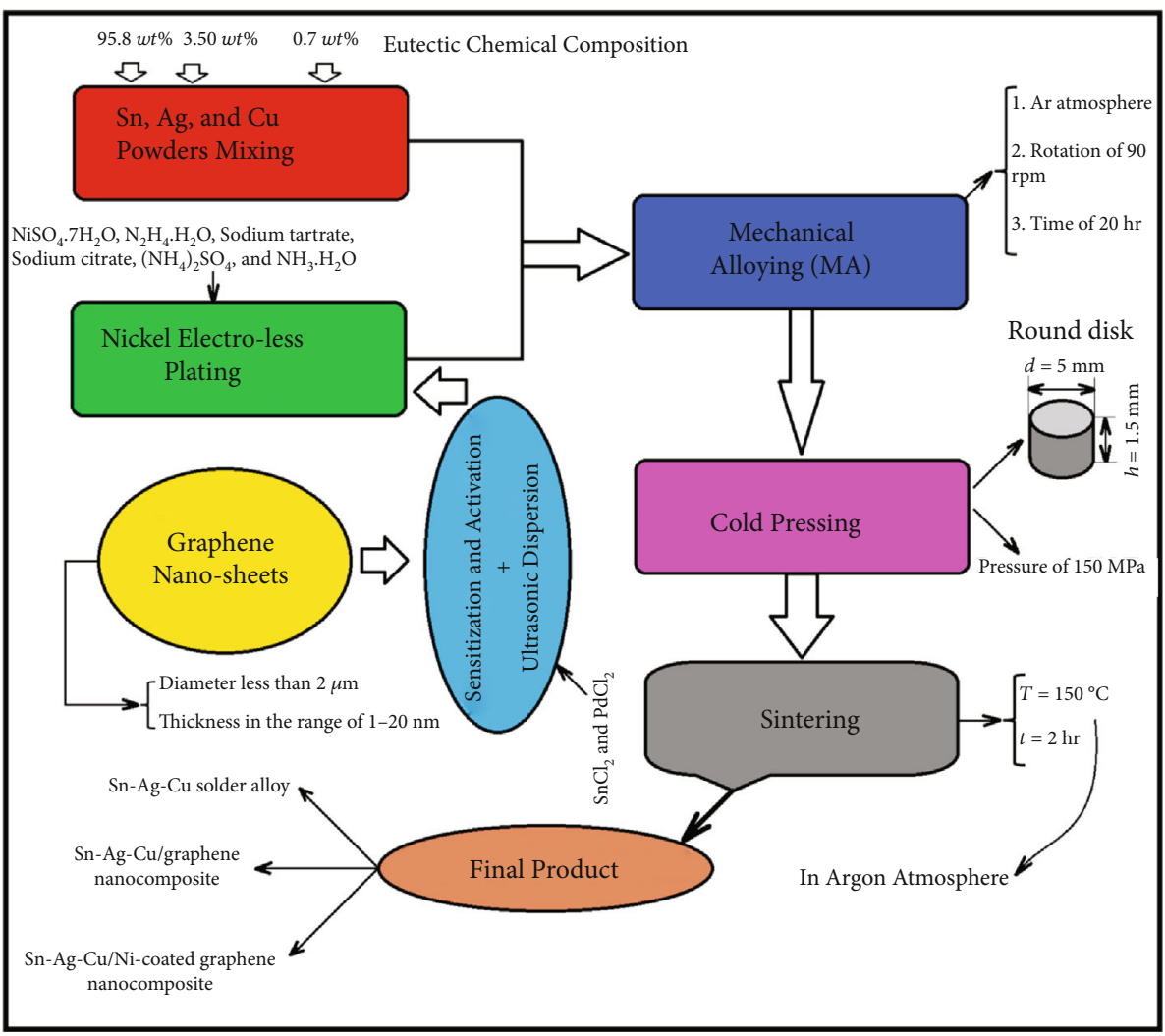

FIgURE 2: Schematic diagram of specimen fabrication process for the undecorated and decorated solders [47].

In the development of new novel solder alloys, the wettability of solder alloys is an important index. In present, the wettability of solder alloys is always assessed through the indicators of spreading area, wet angle, and spreading ratio. In the spreading experiment, a certain quality of solder alloys is placed on the center of base metal, then heated in furnace and held for a few minutes. The samples are taken out after the heating process and cooled to room temperature naturally. The spreading area is calculated by using the ImagePro plus software after the image of spreading morphology is got through a digital camera. The wet angle and spreading ratio are always got with an indirect experiment method 


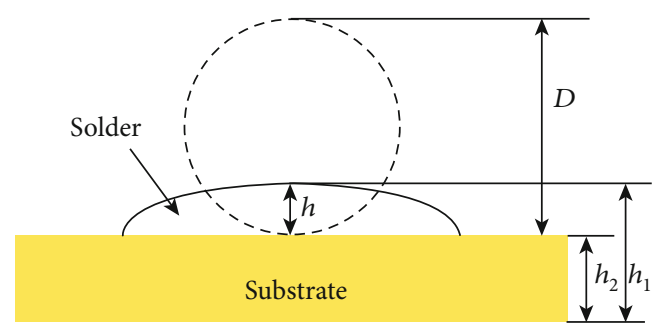

FIGURE 3: Sketch diagram of wettability spreading experiment [49].

whose sketch diagram of measurement mechanism is displayed in Figure 3, where the solder is assumed to be spherical with the diameter $d$. The spreading ratio of solder alloys can be given by [49]

$$
L(\%)=\frac{(d-h)}{d} \times 100 \%=1-\frac{1}{\left[1+3(\cos \theta / 2)^{2}\right]^{1 / 3}},
$$

where $L$ is the spreading ratio, $\theta$ represents the wet angle, and $d$ is the diameter of the solder assumed as a sphere, which is proceeded as

$$
d=2\left[\frac{3\left(m_{2}-m_{1}\right)}{4 \pi \rho}\right]^{1 / 3}
$$

where $\left(m_{2}-m_{1}\right)$ represents the weight of solder, $m_{2}$ and $m_{1}$ are the weights of solder joint and substrate, respectively, and $\rho$ is the density of the composite solder, which can be expressed as

$$
\rho=\frac{M_{\text {solder }}+M_{\text {addition }}}{M_{\text {solder }} / \rho_{\text {solder }}+M_{\text {addition }} / \rho_{\text {addition }}},
$$

where $h$ represents the height of composite solder which can be given by

$$
h=h_{1}-h_{2}
$$

where $h_{1}$ represents the thickness of composite solder joint after soldering and $h_{2}$ represents the thickness of substrate.

\section{Evolution of Microstructure and Properties}

3.1. $\mathrm{Sn}-\mathrm{Ag}-\mathrm{Cu}$. Sn-Ag-Cu solder is the best substitution in the replace of $\mathrm{Sn}-\mathrm{Pb}$ solder. However, with the miniaturization of electron components and deterioration of the service environment, the higher requirements are put forward for the comprehensive properties of SAC solders [62-64]. Therefore, lots of measures had been carried out to enhance the comprehensive performance of SAC solders. And the measures of the addition of alloy elements [12], oxide [65], nanometer metal particles $[66,67]$, carbon nanotubes (CNTs) $[37,68]$, and graphene [39] into plain solder had been proved to be beneficial methods to modify the microstructure and mechanical properties.

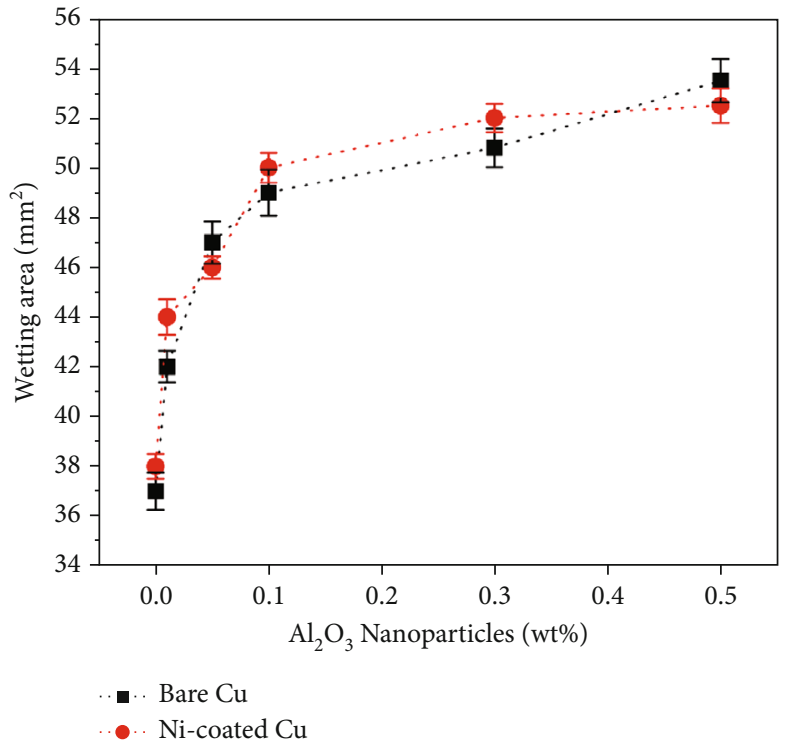

FIgURE 4: The influence of $\mathrm{Al}_{2} \mathrm{O}_{3}$ nanoparticles incorporation on spreading area of SAC0307 solder for $\mathrm{Cu}$ and Ni-P coated $\mathrm{Cu}$ substrates [21].

3.1.1. Wettability. It is well known that the wettability is a significant indicator to evaluate the properties of solder alloys in the field of electronic packaging. Consequently, the wettability of solder alloys is also studied as an important criterion for evaluating the solderability. For the novel composite solder alloys in electronic packaging, most investigations have confirmed that adding trace amount of nanometer particles to the solder substrate will affect the wettability of the solder alloys to some extent. The composite SAC- $x \mathrm{ZnO}$ solder alloys were fabricated with the $\mathrm{ZnO}$ particles ranging from 0 to $2.0 \mathrm{wt} \%$ by Qu et al. [49]. They pointed out that the wettability of solder alloys improved due to the addition of $\mathrm{ZnO}$ nanoparticles and the optimum doping was $0.5 \mathrm{wt} \%$. The effect of $\mathrm{Al}_{2} \mathrm{O}_{3}$ nanoparticles on the wettability of SAC0307 solder alloys was investigated by Tikale and Prabhu [21]. It was found that the spreading area of SAC0307- $x \mathrm{Al}_{2} \mathrm{O}_{3}$ composite solder alloy improved by $15-40 \%$ with the addition range from the 0.01 to $0.5 \mathrm{wt} \%$, as shown in Figure 4 . Gu et al. [55] demonstrated that the wettability of SAC107- $x \mathrm{Fe}_{2} \mathrm{O}_{3}$ composited improved due to the doping of $\mathrm{Fe}_{2} \mathrm{O}_{3}$ nanoparticles and the wettability enhanced first and then decreased with the increase of doped $\mathrm{Fe}_{2} \mathrm{O}_{3}$ nanoparticles content. Additionally, they also confirmed that the dimension of $\mathrm{Fe}_{2} \mathrm{O}_{3}$ nanoparticles could affect the wettability of SAC105$0.5 \mathrm{Fe}_{2} \mathrm{O}_{3}$ composite solder alloy. They pointed out that the wettability of SAC105- $0.5 \mathrm{Fe}_{2} \mathrm{O}_{3}$ composite solder alloy reduced when the size of doped $\mathrm{Fe}_{2} \mathrm{O}_{3}$ nanoparticles changed from $20 \mathrm{~nm}$ to $200 \mathrm{~nm}$; the details are shown in Figure 5 [54]. Sun et al. [69] pointed out that the doping of Al nanoparticles had no evident effect on the melting point of SAC105 solder. However, the wettability of modified SAC105 solder improved obviously, and the optimum additive content of Al nanoparticles was $0.1 \mathrm{wt} \%$.

Sharma et al. [39] studied the effect of the incorporation of graphene nanoplatelets (GNPs) on the evolution of 


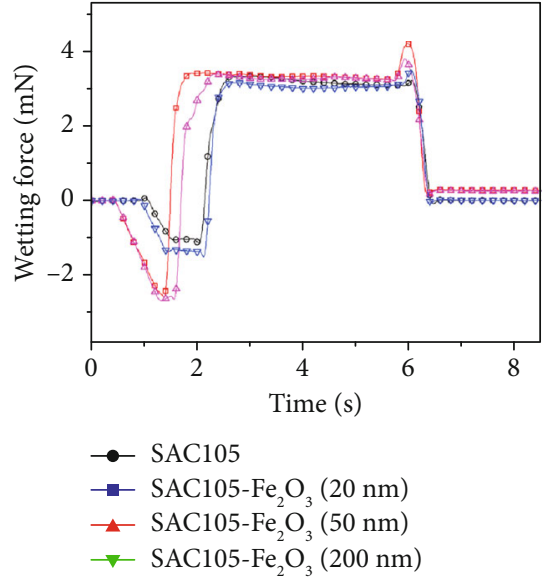

(a)

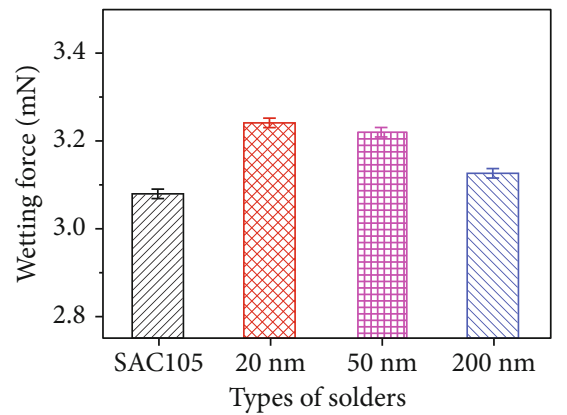

SAC105

SAC105- $\mathrm{Fe}_{2} \mathrm{O}_{3}(20 \mathrm{~nm})$

(1) $\mathrm{SAC} 105-\mathrm{Fe}_{2} \mathrm{O}_{3}(50 \mathrm{~nm})$

$\mathrm{SAC} 105-\mathrm{Fe}_{2} \mathrm{O}_{3}(200 \mathrm{~nm})$

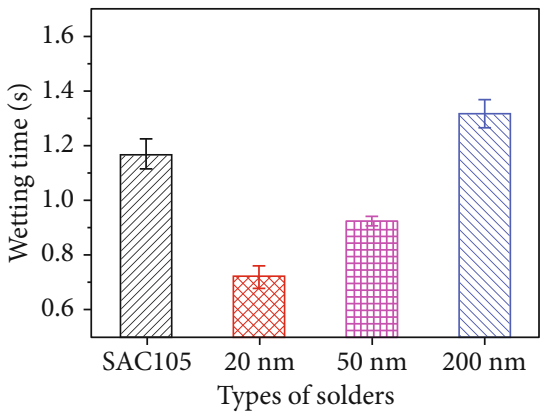

SAC105

$\mathrm{SAC} 105-\mathrm{Fe}_{2} \mathrm{O}_{3}(20 \mathrm{~nm})$

$\mathrm{SAC} 105-\mathrm{Fe}_{2} \mathrm{O}_{3}(50 \mathrm{~nm})$

$\mathrm{SAC} 105-\mathrm{Fe}_{2} \mathrm{O}_{3}(200 \mathrm{~nm})$

(b)

FIGURE 5: The wettability of the SAC105- $\mathrm{Fe}_{2} \mathrm{O}_{3}$ composite solders: (a) wetting curves, (b) wetting force, and (c) wetting time of the plain $\mathrm{SAC105}$ solder and SAC105- $\mathrm{Fe}_{2} \mathrm{O}_{3}$ composite solder alloy with various dimensions of nanoparticles of $200 \mathrm{~nm}, 50 \mathrm{~nm}$, and $20 \mathrm{~nm}$, respectively [54].

wettability of SAC305 solder alloys. They pointed out that SAC305-0.05 wt\% composite solder alloy had the optimum wettability compared with plain SAC305 solder alloy, as shown in Figure 6. Chen et al. [41] researched the influence of the incorporation of fullerenes (FNSs) on the evolution of wettability of SAC305 solder alloys. They pointed out that the incorporation of FNSs could enhance the wettability of the SAC305-FNSs composite solder judging from the contact angle. As mentioned above, it was concluded the incorporation could affect the wettability of solders and the relevant generalized in Table 2.

3.1.2. Microstructure of Composite Solder Joints. The microstructure of solder alloys could be affected due to the addition of nanometer particles, then resulted in the improvement of mechanical properties of composite solder alloys. The addition of nanometer particles provides lots of nucleation points, which leads to the refinement of IMC in the solder matrix; then, the mechanical performance of composite solder alloy increased. Daly et al. [72] demonstrated that the dimensions of $\beta$-Sn and IMC decreased obviously due to the doping of nanosized $\mathrm{ZnO}$ particles into the SAC305 solder alloy. And the evolution of microstructure of SAC305-ZnO composite solder alloy was mainly associated with the nucleation effect of $\mathrm{ZnO}$ nanoparticles. Qu et al. [49] pointed out that the incorporation of $\mathrm{ZnO}$ particles could reduce the thickness of the IMC layer as a solder and the growth rate of interface IMC layer during aging. The change of morphology of IMC layer of composite solder joints and plain SAC305 solder joint during aging was different, as shown in Figure 7. In addition, the voids and cracking appeared for the plain SAC305 solder joint with the increase of aging time. However, there was no obvious voids and cracking for the SAC305-ZnO composite solder joints. Moreover, the suppressed effect of the growth of IMC layer due to the addition of $\mathrm{ZnO}$ particles was also reported by Peng et al. [53, 73]. Tikale and Prabhu [21] studied the effect of the incorporation of $\mathrm{Al}_{2} \mathrm{O}_{3}$ nanoparticles with different contents

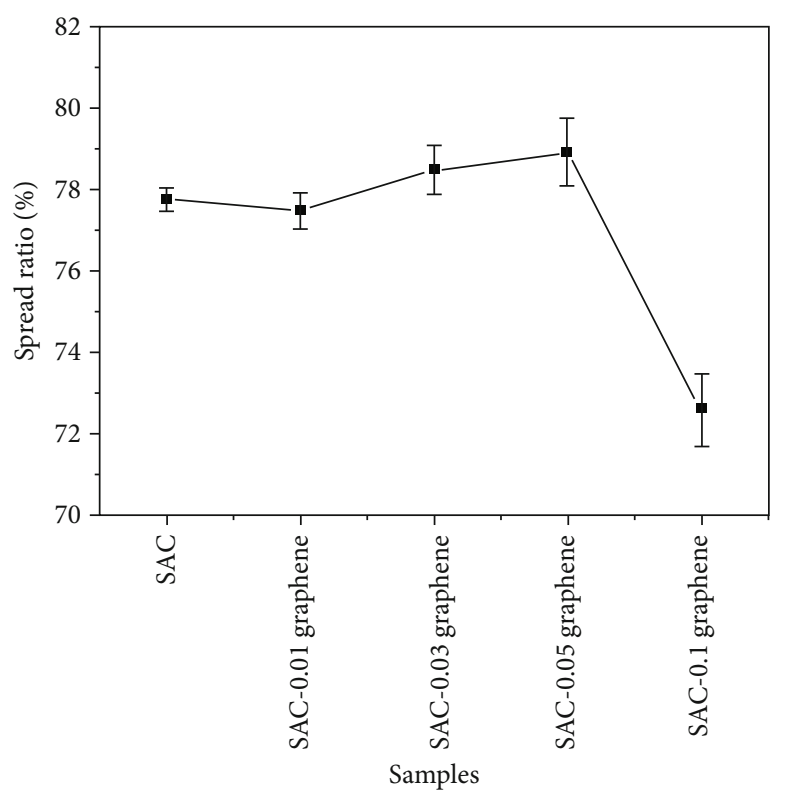

FIgURE 6: Spreading rate of plain SAC and composite solder with different graphene contents [39].

on the evolution of microstructure of SAC0307/Cu solder joints under multiple reflows, as shown in Figure 8. They pointed out that the morphology characteristics of $\mathrm{Cu}_{6} \mathrm{Sn}_{5}$ transformed from columnar-shaped to rounded-scallop form and the $\mathrm{Ag}_{3} \mathrm{Sn}$ also transformed from the elongated-shaped morphology to ultrafine-spheroidal. It was found that the doping of $\mathrm{Al}_{2} \mathrm{O}_{3}$ nanoparticles inhibited the growth of IMC, as displayed in Figure 9. In addition, the inhibiting effect to the growth of IMC of SAC solder joint due to the addition of nanometer particles is also demonstrated by Zhao et al. [74] and Gain et al. [75]. Wu et al. [76] investigated the coupling influence of Pr and alumina oxide nanoparticles on the transformation of microstructure of SAC0307 solder. It was 
TABLE 2: The effect of incorporation on the wettability of SAC composite solder.

\begin{tabular}{|c|c|c|}
\hline Sn-Ag-Cu based solder & Wettability & Optimum addition \\
\hline Sn-Ag-Cu-ZnO [49] & $\begin{array}{l}\mathrm{ZnO} \text { addition resulted in the decrease of wetting angles, which implies } \\
\text { the improvement of wettability }\end{array}$ & $0.5 \mathrm{wt} \%$ \\
\hline $\mathrm{Sn}-\mathrm{Ag}-\mathrm{Cu}-\mathrm{Al}_{2} \mathrm{O}_{3}[21]$ & $\begin{array}{c}\text { Addition of } \mathrm{Al}_{2} \mathrm{O}_{3} \text { with the range of } 0.01-0.5 \mathrm{wt} \% \text { resulted in } \\
\text { the increase of wetting area }\end{array}$ & - \\
\hline $\mathrm{Sn}-\mathrm{Ag}-\mathrm{Cu}-\mathrm{Fe}_{2} \mathrm{O}_{3}[55]$ & $\begin{array}{l}\text { Wettability increases first and then decreases with the increase of addition } \\
\text { ranged from } 0 \text { to } 1 \mathrm{wt} \%\end{array}$ & $0.4 \mathrm{wt} \%$ \\
\hline $\mathrm{Sn}-\mathrm{Ag}-\mathrm{Cu}-\mathrm{La}_{2} \mathrm{O}_{3}[56]$ & $\begin{array}{l}\text { Spreading area increases with the addition range from } 0 \text { to } 0.05 \% \mathrm{La}_{2} \mathrm{O}_{3} \text {, } \\
\text { then decreases in } 0.1 \mathrm{wt} \% \mathrm{La}_{2} \mathrm{O}_{3}\end{array}$ & $0.05 \mathrm{wt} \%$ \\
\hline Sn-Ag-Cu-CuZnAl $[70,71]$ & $\begin{array}{l}\text { Spreading ratio improvement and contact angle decreased due to the } \\
\text { addition of } \mathrm{CuZnAl} \text { particles }\end{array}$ & $0.5 \mathrm{wt} \%$ \\
\hline Sn-Ag-Cu-TiC [30] & $\begin{array}{c}\text { Contact angles of composite solder reduced first and then improved } \\
\text { with the increase of } \mathrm{TiC} \text { content }\end{array}$ & $0.1 \mathrm{wt} \%$ \\
\hline Sn-Ag-Cu-nano-Al [69] & $\begin{array}{c}\text { Wetting area increases with the improvement of } \mathrm{Al} \text { nanoparticles } \\
\text { when the content is less than } 0.1 \mathrm{wt} \% \text {, and then the wettability } \\
\text { deteriorates with the increase of } \mathrm{Al} \text { nanoparticles when the } \\
\text { content is more than } 0.1 \mathrm{wt} \%\end{array}$ & $0.1 \mathrm{wt} \%$ \\
\hline Sn-Ag-Cu-GNPs [39] & $\begin{array}{l}\text { Spreading ratio improves gradually with the increase of GNPs and } \\
\text { achieved an optimum value with the content of } 0.05 \mathrm{wt} \% \text {, then } \\
\text { deteriorated in } 0.1 \mathrm{wt} \% \text { addition }\end{array}$ & 0.05 wt $\%$ \\
\hline Sn-Ag-Cu-FNSs [41] & $\begin{array}{l}\text { Contact angle decreased first then decreased with the increase } \\
\text { of FNSs content }\end{array}$ & $0.1 \mathrm{wt} \%$ \\
\hline
\end{tabular}

found that the morphology feature of $\mathrm{Cu}_{6} \mathrm{Sn}_{5}$ in the SAC0307-0.06Pr-0.03wt $\% \mathrm{Al}_{2} \mathrm{O}_{3}$ composite solders alloy changed from long strip-shaped to short rod-shaped, as shown in Figure 10 [76]. Furthermore, both the dimension and morphology of $\mathrm{Cu}_{6} \mathrm{Sn}_{5}$ changed with the increasing of the addition content of $\mathrm{Al}_{2} \mathrm{O}_{3}$ to $0.06 \mathrm{wt} \%$.

Tang et al. [25, 77, 78] studied the influence of $\mathrm{TiO}_{2}$ nanoparticles on the evolution of IMC growth of SAC305$x \mathrm{TiO}_{2}$ composite solder joints systematically. They pointed out that the doping of $\mathrm{TiO}_{2}$ nanoparticles had positive influence in inhibiting the growth of IMC layers and the thickness of IMC increase rapidly with the increase of isothermal aging time and temperature [77]. More specifically, the growth of $\mathrm{Cu}_{6} \mathrm{Sn}_{5}$ layer was affected obviously by the addition of $\mathrm{TiO}_{2}$ nanoparticles and there is no evident influence on the change of $\mathrm{Cu}_{3} \mathrm{Sn}$ layer and the optimum addition of $\mathrm{TiO}_{2}$ nanoparticles was $0.1 \mathrm{wt} \%$ considering the suppressing effect on the growth of IMC layer [78]. A similar inhibiting effect of the incorporation of $\mathrm{TiO}_{2}$ nanoparticles into the SAC solder alloy on the growth of IMC layer is also proved by the other investigators $[26,27,79]$. Moreover, the other oxides, such as $\mathrm{Fe}_{2} \mathrm{O}_{3}[54,55], \mathrm{CeO}_{2}[57,65], \mathrm{SrTiO}_{3}[80], \mathrm{ZrO}_{2}$ [29], and $\mathrm{La}_{2} \mathrm{O}_{3}$ [56], are doped into SAC solder alloys to adjust the microstructure and then modified the mechanical performance ultimately. The relevant investigations proved that all of the above-mentioned oxides displayed positive influence in suppressing the coarsening of IMC. Apart from oxide, the carbide of $\mathrm{TiC}$ and $\mathrm{SiC}$ nanoparticles is also added to adjust the microstructure of SAC solder alloy [30, 31, 81].

Some metal nanometer particles were also incorporated with SAC solder alloy. Sun et al. [69] confirmed that the addition of $\mathrm{Al}$ nanoparticles could refine the microstructure of SAC105- $x$ Al composite solder alloy. The growth rate of
IMC in the SAC105- $x \mathrm{Al} / \mathrm{Cu}$ solder joint decreased compared with that in the plain SAC105/Cu solder joint during aging. The inhibition effect on the growth rate of IMC in $\mathrm{SAC} / \mathrm{Cu}$ solder joints was also observed because of the addition of Mo [67], Cu [82], and diamond [58] nanoparticles.

In addition, some investigations also proved that the incorporation of GNSs or CNTs could change the microstructure of SAC solder. Huang et al. [83] confirmed that doping of GNSs could result in the transformation of microstructure of solder alloys. Specifically speaking, the size of $\beta$ Sn structure reduced while the volume fraction of eutectic structure increased, as shown in Figure 11. Zhu et al. [37] investigated the influence of the dimension of CNTs on the change of microstructure of CNT-additive SAC0307-CNT composite solder alloy, as shown in Figure 12. It was found that the inhibiting effect of IMC growth was associated with the adsorption of CNTs on the surface of IMC; the schematic diagram of adsorption and segregation is shown in Figure 13. The integrity of the IMC layers was destroyed due to the adsorption of CNTs; then, the growth of IMC was suppressed. Furthermore, the influence of addition of Ag-coated [84] and Ni-modified [46] graphene on the microstructure evolution of SAC composite solder alloys was discussed. Kumar et al. $[85,86]$ confirmed that the addition of CNTs could refine the microstructure of SAC solder. The other carbon-based nanomaterials of FNSs was also added into SAC305 solder $[41,43]$. They confirmed that the grain size of $\beta$-Sn displays an evident reduction trend with the addition of FNSs. Additionally, the size of $\mathrm{Ag}_{3} \mathrm{Sn}$ also reduced due to the addition of FNSs, as shown in Figure 14.

3.1.3. Mechanical Properties. The mechanical and electric connections are provided by solder joints for the electrical 

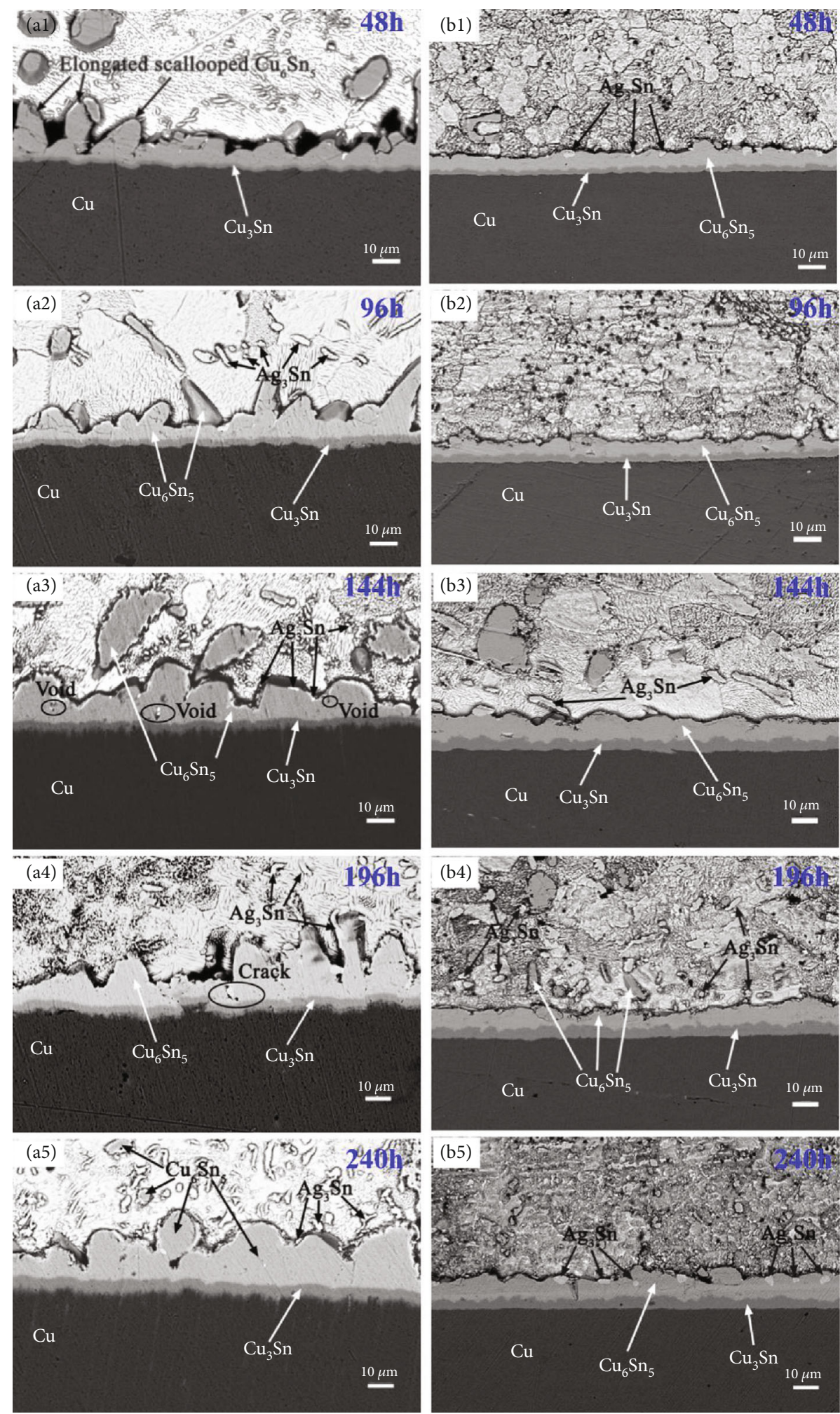

FIGURE 7: SEM microstructure of SAC305 solder joints on the left side (a1-a5) and SAC305-0.5 wt\%ZnO composite solder joints on the right side (b1-b5) [49].

components [65, 87-89]. Consequently, the reliability of the package structure in the service conditions was determined by the mechanical properties of solder joints. The effect of the additions on the mechanical properties of solder joints is investigated widely [90-93]. Lots of investigations had proved that the addition of nanometer particles could enhance the mechanical properties of novel composite solder joints. Daly et al. [72] found that the ultimate tensile strength 


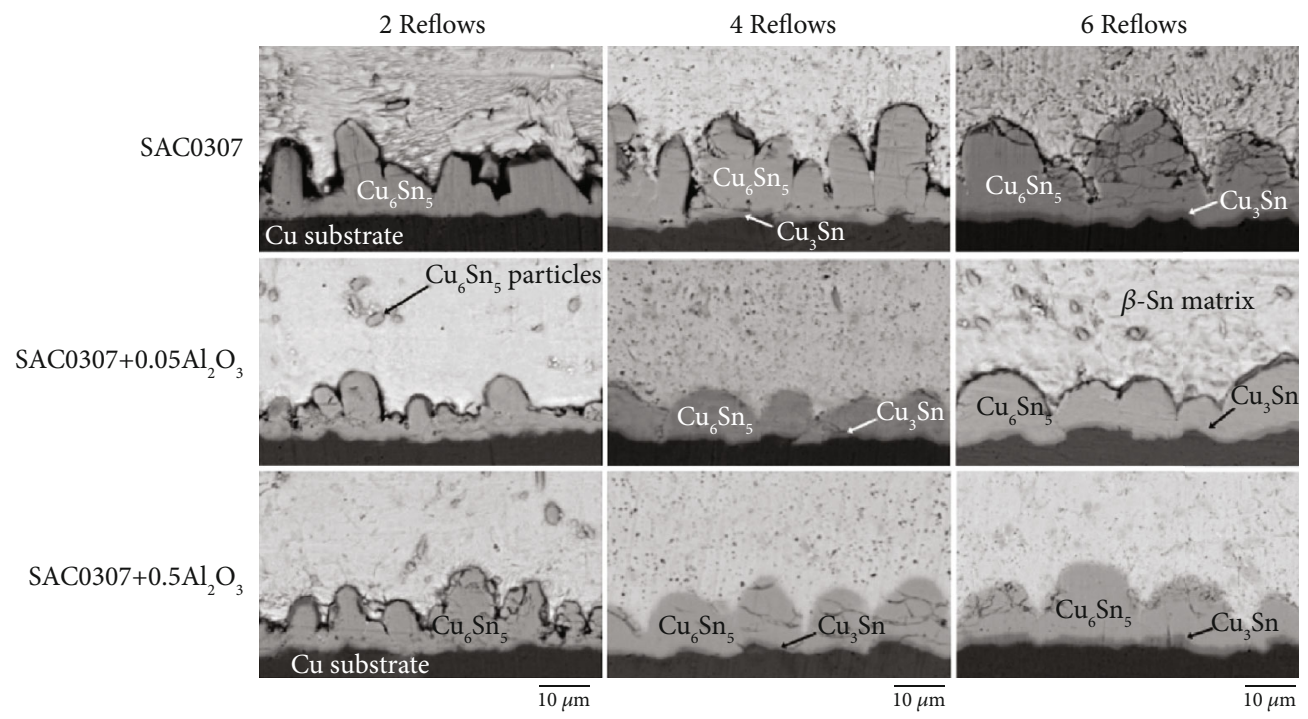

Figure 8: SEM images of the interface of solder joint for various SAC0307- $x \mathrm{Al}_{2} \mathrm{O}_{3}$ composites under multiple reflow cycles [21].

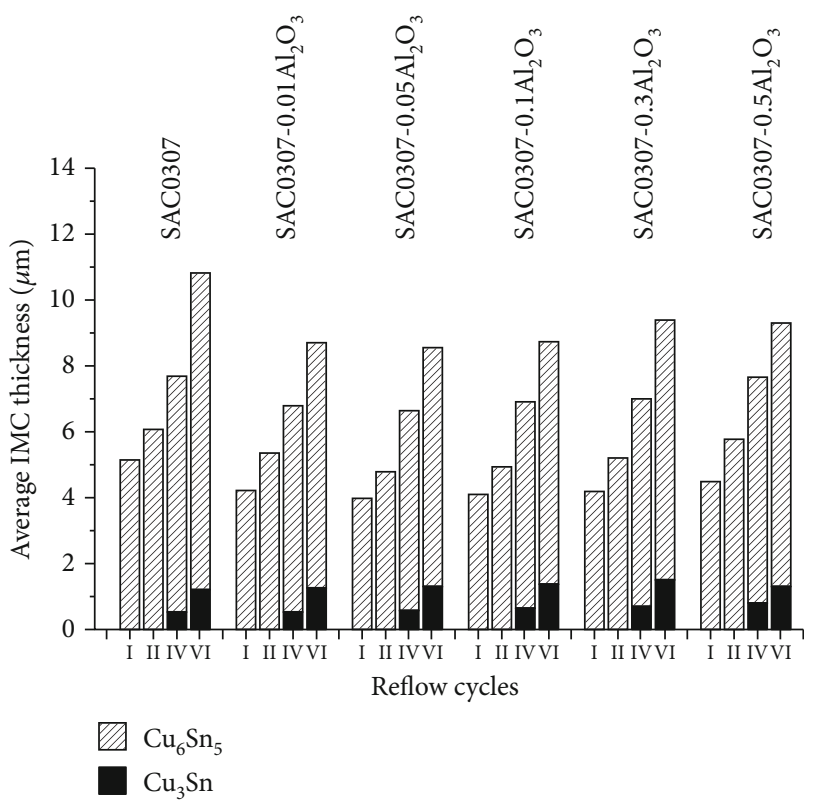

Figure 9: Influence of the reflow cycles on the thickness of IMC for different additions of $\mathrm{Al}_{2} \mathrm{O}_{3}$ [21].

(UTS) and yield stress of SAC305-0.7\% ZnO composite solder alloy increased significantly compared with the plain SAC305 solder alloy. However, the ductility was lower than that of the plain SAC305 solder alloy. Fawzy et al. [73] confirmed that the creep lifetime of SAC355-ZnO composite solder alloy increased because of the incorporation of $\mathrm{ZnO}$ nanoparticles, and the main reason was likely associated with refinement of microstructure. Hammad and Ibrahiem [51] demonstrated that the tensile creep resistance of SAC305 composite solder alloy increased compared with the plain SAC305 solder alloy, which attributed to the refinement of microstructure.

The transformation of mechanical properties of SAC0307 solder alloy with the incorporation of $\mathrm{Al}_{2} \mathrm{O}_{3}$ nano- particles with different addition content is estimated by Tikale and Prabhu [21]. It was found that the microhardness of SAC0307 solder increased by 10-55\% with the doping of aluminum oxide nanoparticles in the range of $0.01-0.5 \mathrm{wt} \%$ and the increasing trend of microhardness became slower when the addition of $\mathrm{Al}_{2} \mathrm{O}_{3}$ nanoparticles was higher than that of $0.1 \mathrm{wt} \%$, as shown in Figure 15. In addition, the shear strength of the composite solder increased with the doping of aluminum oxide nanoparticles. Gain et al. [75] demonstrated that both the elastic moduli and shear force of SAC305 composite solder alloy with the addition of $\mathrm{Al}_{2} \mathrm{O}_{3}$ nanoparticles displayed higher value than that of plain SAC305 solder alloy due to the influence of dispersion strengthening. However, Zhao et al. [74] pointed out that the reliability of solder joints was improved due to the addition of $\mathrm{Al}_{2} \mathrm{O}_{3}$ nanoparticles, while the strength had no obvious change. Wu et al. [76] estimated the effect of synergistic effect of the incorporation of $\operatorname{Pr}$ and $\mathrm{Al}_{2} \mathrm{O}_{3}$ nanoparticles on the mechanical properties of SAC0307 solder joints, as shown in Figure 16. It was found that the doping of $\mathrm{Al}_{2} \mathrm{O}_{3}$ nanoparticles displayed an evident effect on the shear strength of the composite solder alloys, which increased originally and then decreased with the addition content of $\mathrm{Al}_{2} \mathrm{O}_{3}$ nanoparticles from 0 to $0.5 \mathrm{wt} \%$. The evolution of shear strength is mainly associated with the change of morphology and the thickness IMC [76]. Namely, the thickness of IMC of SAC0307 composite solder joints decreases first and then increases gradually.

The intermetallic particles are also added to enhance the performance of SAC solder alloys [32-34]. Hu et al. [34] demonstrated that the mechanical properties of SAC305 solder increased due to the addition of $\mathrm{Cu}_{6} \mathrm{Sn}_{5}$ nanoparticle, which was associated with the refinement of IMC. They also point out that the sizes of the addition $\mathrm{Cu}_{6} \mathrm{Sn}_{5}$ nanoparticles could affect the properties of SAC solder alloys [33]. Sharma et al. [39] studied the influence of GNSs on the mechanical performance of SAC305 solder alloy. They pointed out that the optimum addition was $0.05 \mathrm{wt} \%$. The tensile strength and elongation of composite solder increased by $17.0 \%$ and 


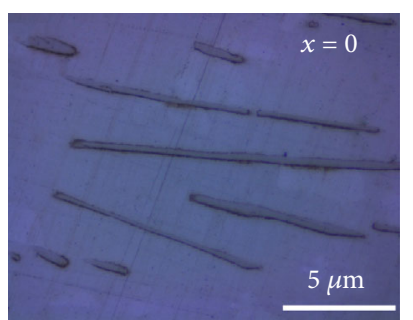

(a)

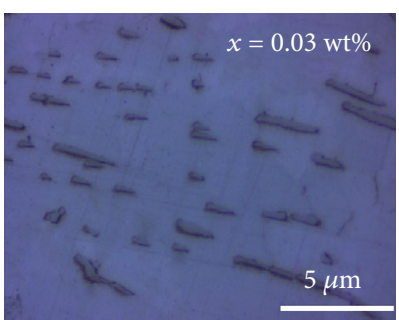

(b)

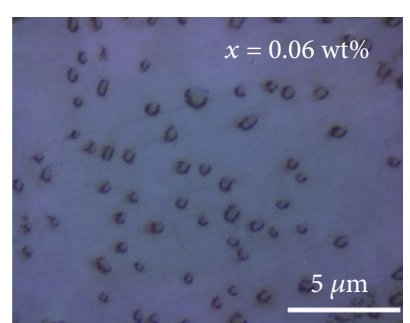

(c)

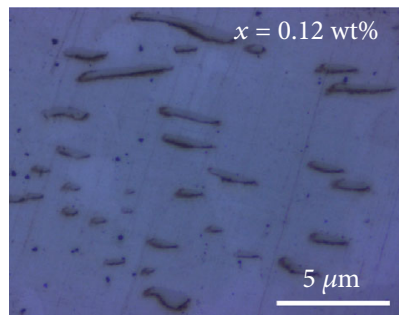

(d)

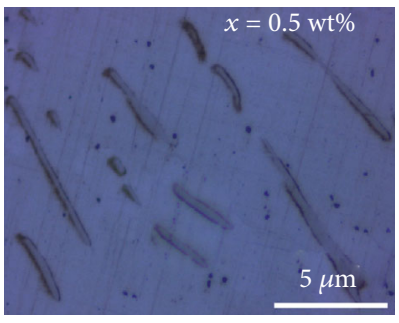

(e)

FIgURE 10: The microstructure evolution of $\mathrm{Cu}_{6} \mathrm{Sn}_{5}$ in the solder of SAC0307-0.06Pr- $x \mathrm{Al}_{2} \mathrm{O}_{3}$ [76].

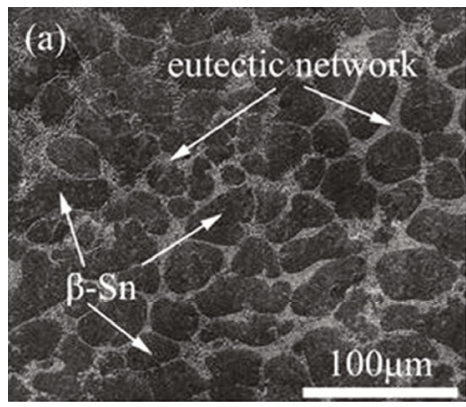

(a)

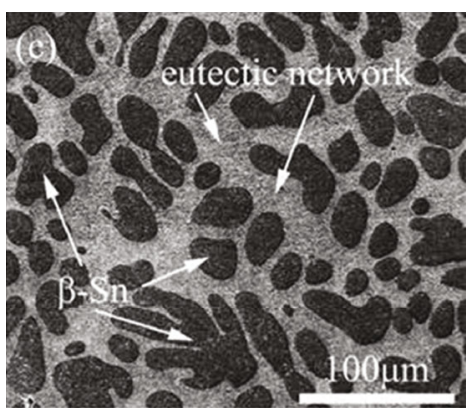

(c)

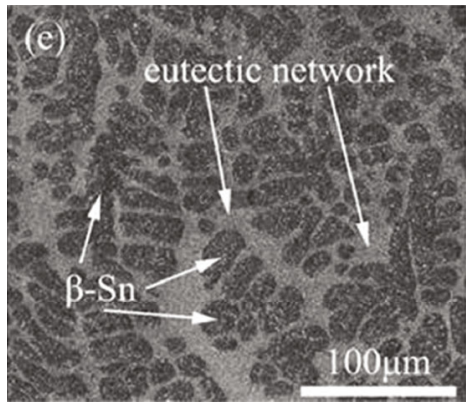

(e)

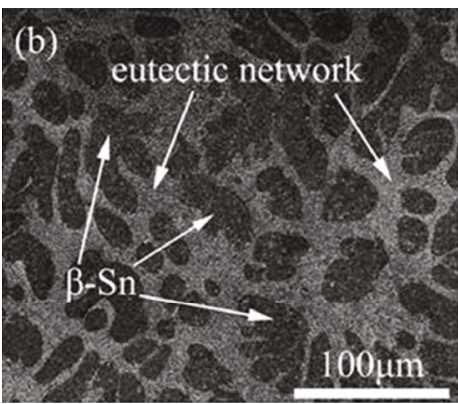

(b)

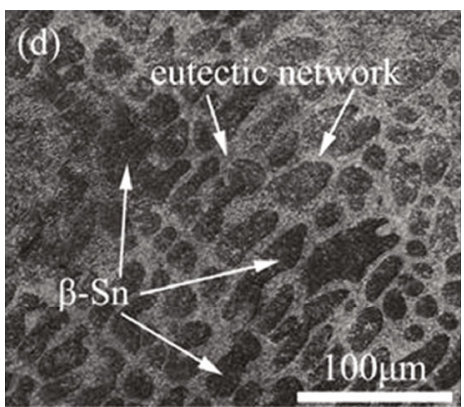

(d)

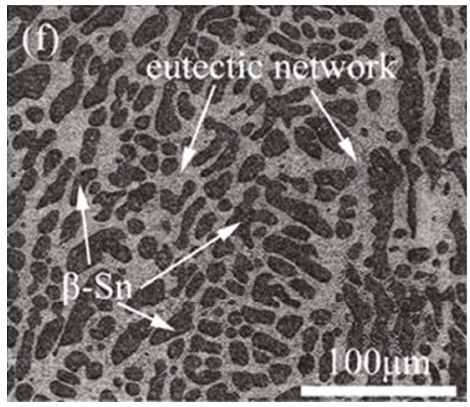

(f)

Figure 11: The transformation of microstructure of solders: (a) SAC, (b) SAC305+0.02GNSs, (c) SAC305+0.04GNSs, (d) SAC305+ 0.06 GNSs, (e) SAC305 + 0.08GNSs, and (f) SAC305 + 0.1GNSs [83]. 

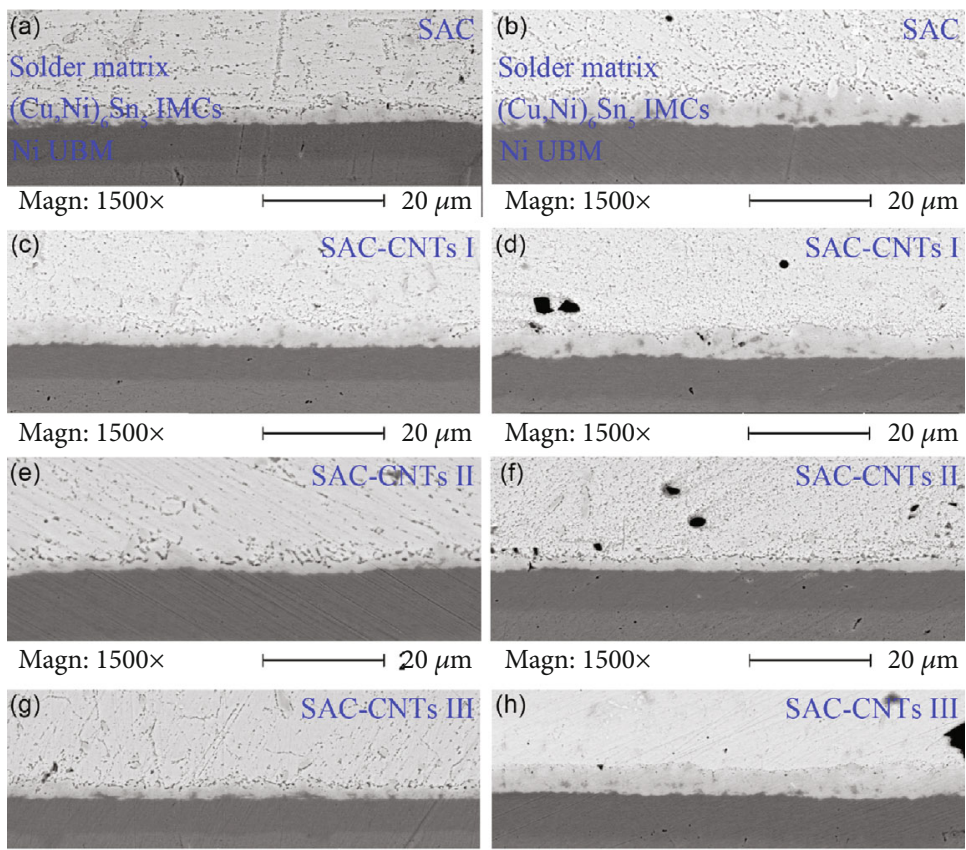

Magn: $1500 \times$

$20 \mu \mathrm{m}$

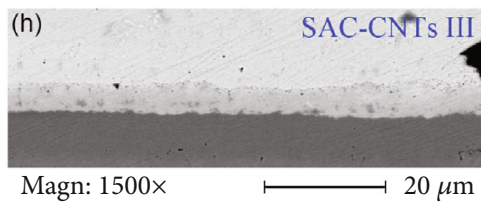

334 hours stressing

600 hours stressing

FIGURE 12: SEM pictures of microstructures in solder joints with different aging times of $334 \mathrm{~h}$ (left side) and $600 \mathrm{~h}$ (right side) at $100^{\circ} \mathrm{C}$ [37].

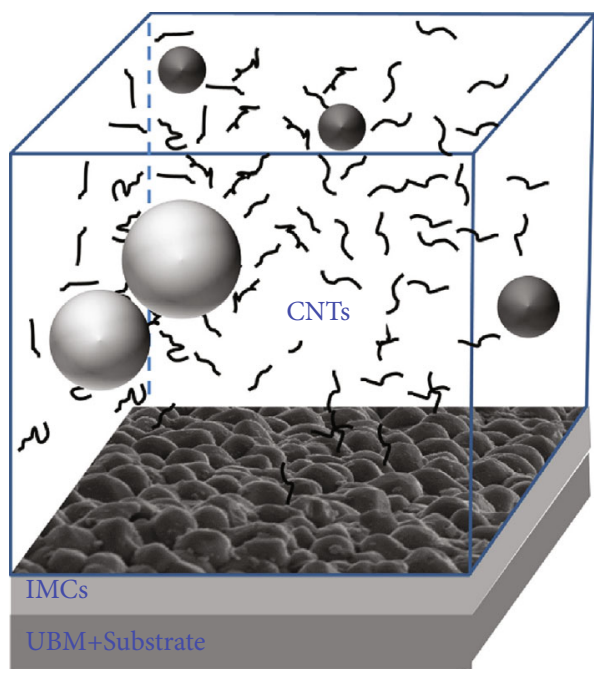

(a)

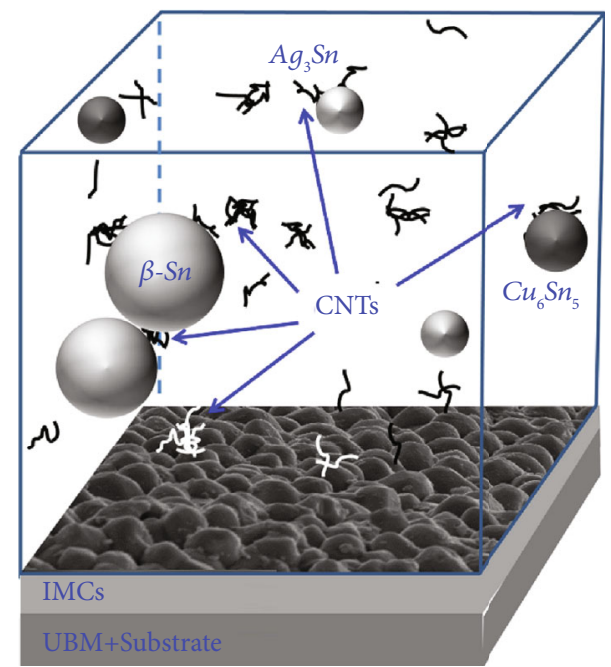

(b)

FIGURE 13: The schematic diagram of adsorption and segregation of CNTs in the solder matrix (a) before segregation and (b) after segregation [37].

$13.9 \%$, respectively, compared with the plain SAC305 solder alloy, as shown in Figure 17. Furthermore, they confirmed that the improvement of mechanical properties was associated the refinement of the IMC, which caused by the addition of GNSs.

Zhu et al. [37] investigated the influence of the dimension of CNTs on the mechanical properties of CNT-additive SAC0307 composite solder alloys. The transmission electron microscope (TEM) pictures of three kinds of CNTs with different diameter ranges are shown in Figure 18. They pointed out that the shear force deteriorated with the increase of aging time for all four kinds of solder joints, as displayed in Figure 19. In addition, three kinds of CNT-additive composite solder joints have better shear strength compared with the plain solder joint. And the sample of SAC-CNT II composite solder joint has the largest shear strength relative to plain solder joints. Furthermore, they pointed out that the increase of shear strength was associated with the refinement of microstructure and increase of dislocation densities, which caused by the addition of CNTs, as shown in Figure 12. Moreover, in 


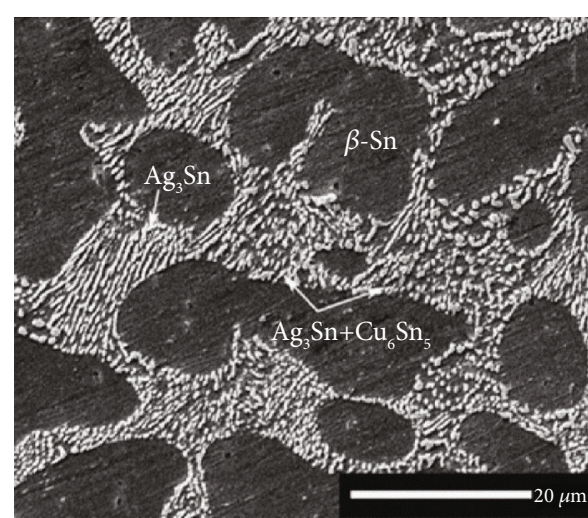

(a)

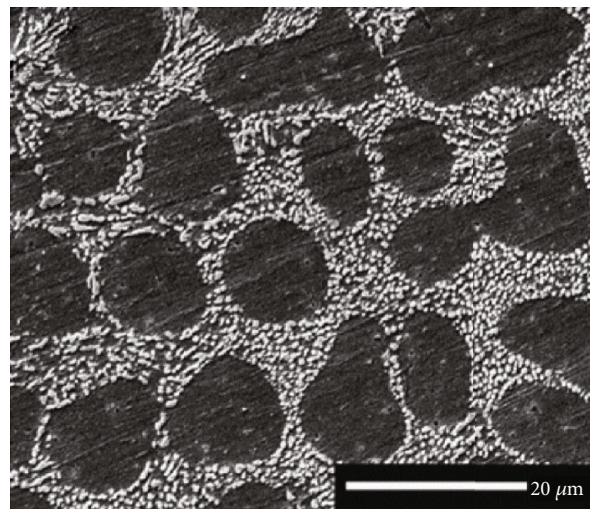

(c)

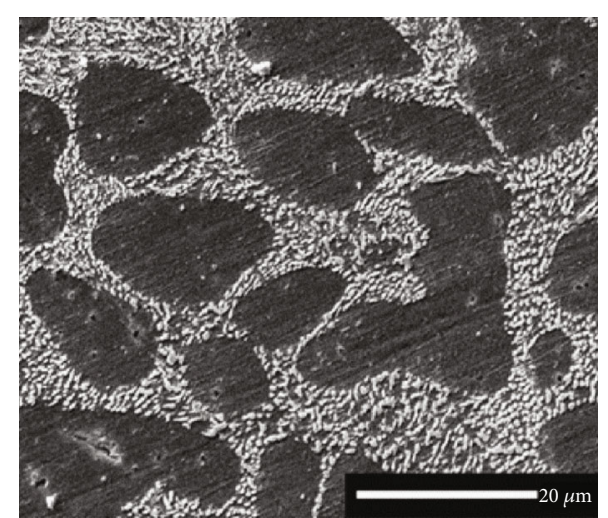

(b)

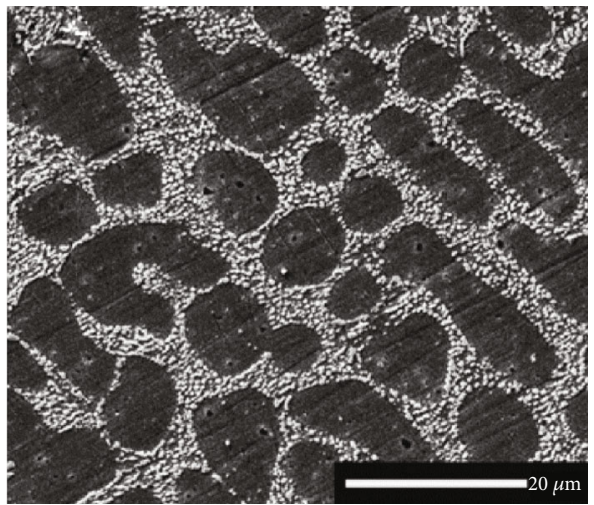

(d)

Figure 14: Microstructure of as-cast solders. (a) SAC305, (b) SAC305/0.05 FNSs, (c) SAC305/0.1 FNSs, and (d) SAC305/0.2FNSs [41].

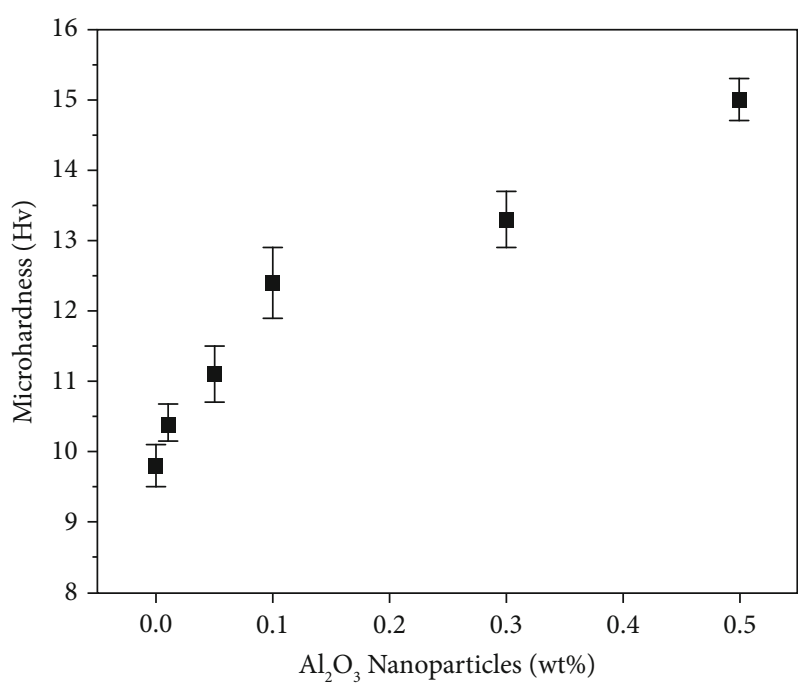

FIGURE 15: Evolution of microhardness of SAC0307 solder with different additions of $\mathrm{Al}_{2} \mathrm{O}_{3}$ nanoparticles [21].

order to overcome the error between designed additions and actual existing content appeared, the influence of addition of Ag-coated [84] and Ni-modified [46] graphene on the mechanical properties of SAC solder was discussed. Kumar et al. $[85,86]$ proved that the doping of CNTs has a positive effect in the enhancement of mechanical properties of SAC

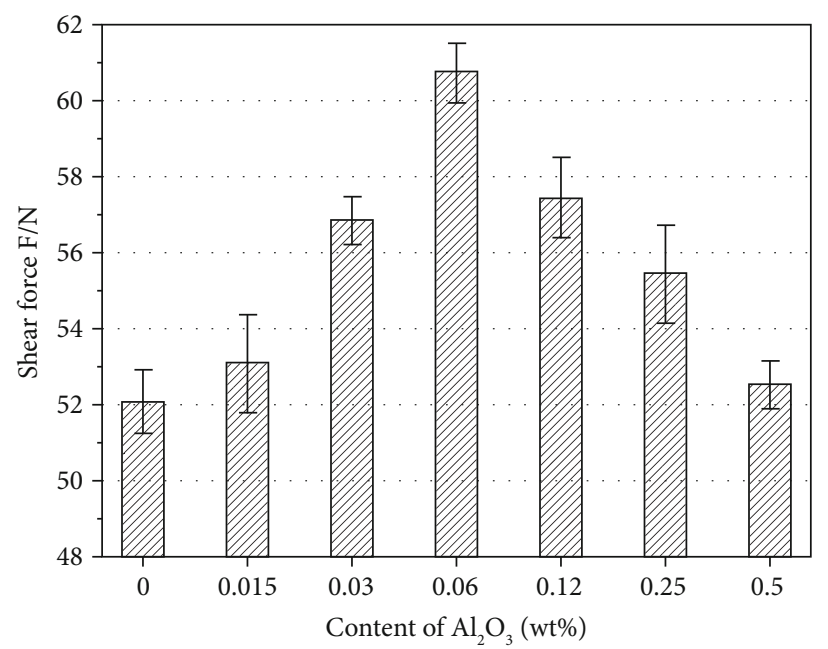

FIgURE 16: The evolution of shear strength of the SAC0307-0.06Pr$x \mathrm{Al}_{2} \mathrm{O}_{3}$ composite solder joints $(x=0-0.5 \mathrm{wt} \%)$ [76].

solder alloy. The addition of FNSs nanoparticles also contributes to the improvement microhardness and shear strength [41].

3.2. $\mathrm{Sn}$-Bi. $\mathrm{Sn}$-Bi solder alloy was also considered as the candidate of traditional $\mathrm{Sn}-\mathrm{Pb}$ solder alloy because of the advantage of lower melting point and cost. However, the 


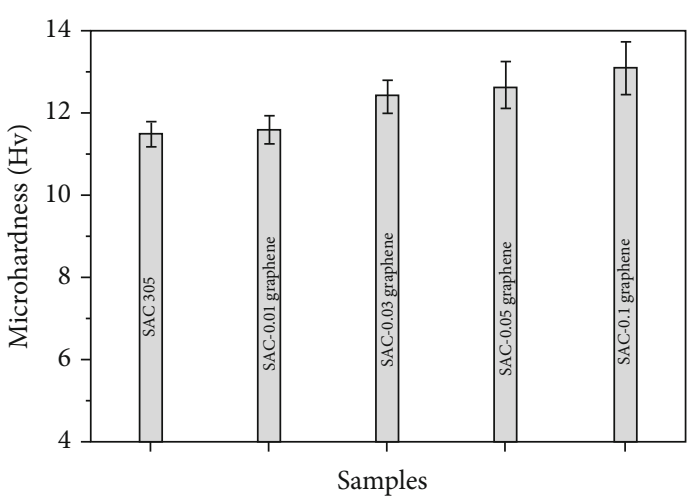

(a)

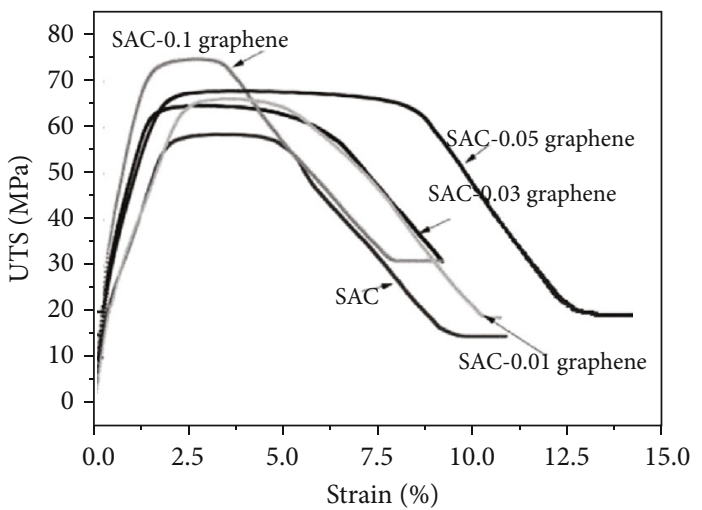

(c)

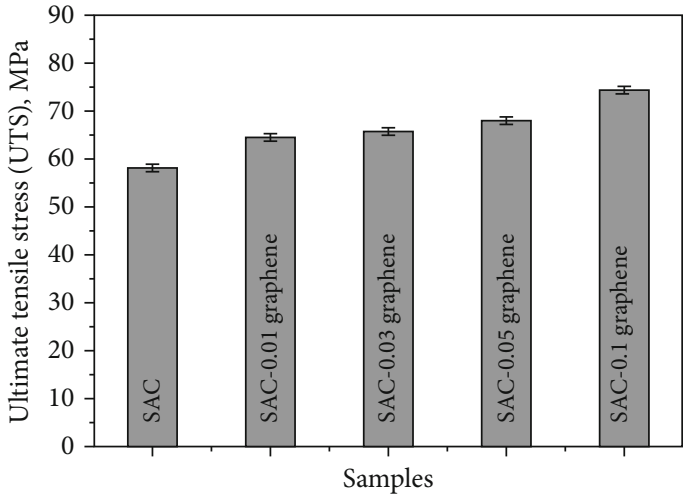

(b)

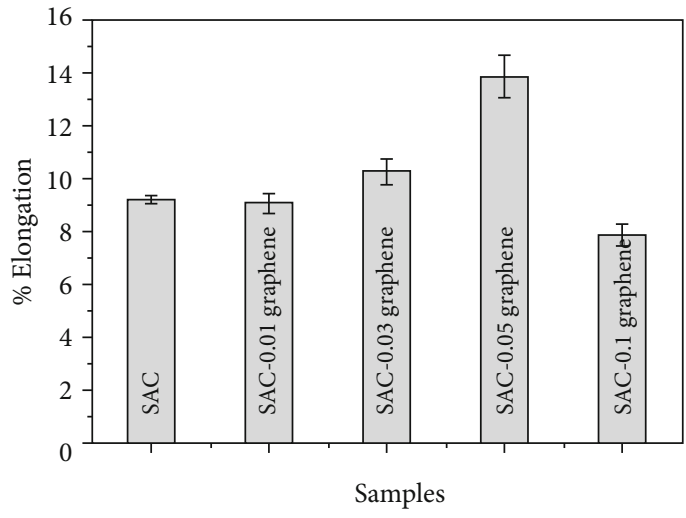

(d)

FIGURE 17: The evolution of mechanical properties of SAC305- $x$ graphene: (a) microhardness; (b) UTS; (c) stress-strain curves; (d) elongation [39].

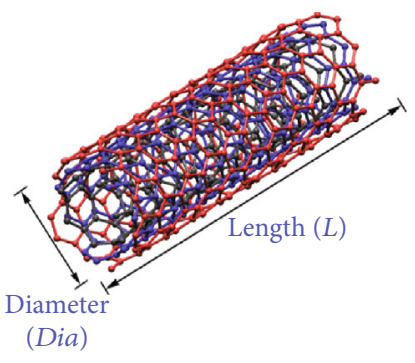

(a)

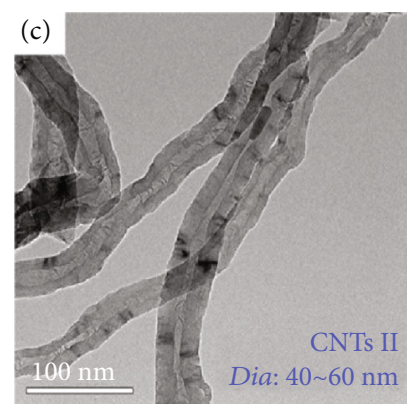

(c)

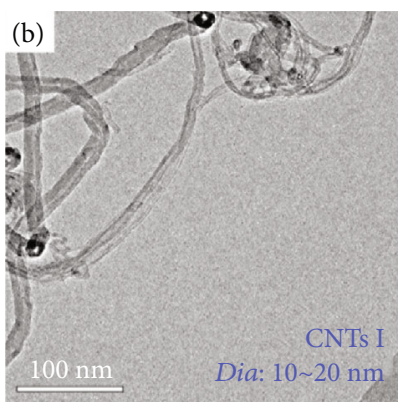

(b)

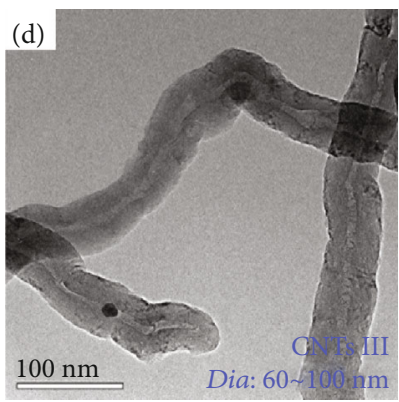

(d)

FIGURE 18: The microstructure of CNTs: (a) diagrammatic drawing of CNT morphology: TEM pictures of different CNTs: (b) CNT I, (c) CNT II, and (d) CNT III [37]. 


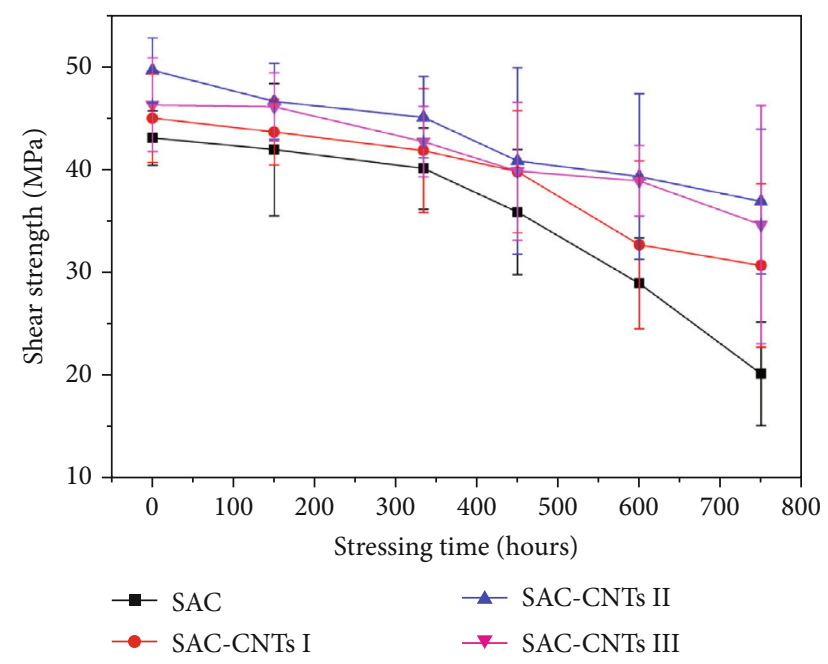

Figure 19: The evolution of shear force of SAC0307-CNT composite solder joints annealed at $100^{\circ} \mathrm{C}$ [37].

application of Sn-Bi solder alloy was hindered to some extent due to the poor wettability and the inherent brittleness of $\mathrm{Bi}$ element itself. Therefore, lots of investigations had been performed to improve the properties of Sn-Bi solder alloys. For example, these are the addition of alloying elements, enhancement of substrate, and fabricating composite solder by doping of chemical compounds. Among these methods, the preparation of composite solder was an effective method to improve the properties of solder alloys.

3.2.1. Wettability. The wettability plays a significant role in evaluating the properties of novel lead-free solder alloys. Liu et al. [23] demonstrated that the spread area increased by $20 \%$ relative to the $\mathrm{Sn}-58 \mathrm{Bi}$ solder alloy when the addition of $\mathrm{Y}_{2} \mathrm{O}_{3}$ was $1 \mathrm{wt} \%$. Yang et al. [22] pointed out that the spreading coefficient of $\mathrm{Sn}-58 \mathrm{Bi}-1 \mathrm{wt} \% \mathrm{BaTiO}_{3}$ increased by $10.24 \%$ compared with the plain solder. The $\mathrm{Sn}-58 \mathrm{Bi}-x \mathrm{CeO}_{2}$ composite solders were prepared by Sharma et al. [94]. And they demonstrated that the spread ratio and wetting angle of $\mathrm{Sn}-58 \mathrm{Bi}-0.6 \mathrm{CeO}_{2}$ composite solders increased by $16.66 \%$ and $32.05 \%$, respectively, compared with the plain solder alloy.

Apart from the oxide, the metal nanoparticles are always chosen to adjust the properties of Sn-Bi solder [95-101]. Gain and Zhang [95] investigated the influence of doping $\mathrm{Ni}$ nanoparticles on the wettability of Sn-Bi-Ag solder. They pointed out that the wetting angle decreased from $33.1^{\circ}$ to $23.4^{\circ}$ and the spreading area increased from $1.48 \mathrm{~mm}^{2}$ for plain solder to $2.07 \mathrm{~mm}^{2}$ for $\mathrm{Sn}-\mathrm{Bi}-\mathrm{Ag}-0.5 \mathrm{Ni}$ solder/Cu substrate due to the addition of $0.5 \mathrm{wt} \% \mathrm{Ni}$ nanoparticles, as displayed in Figure 20. Jiang et al. [97] demonstrated that the doping of Ti nanoparticles was beneficial for the improvement of wettability and the optimum addition was $0.1 \mathrm{wt} \%$.

3.2.2. Microstructure of Solder Joints. The mechanical properties are mainly associated with the evolution of microstructure of solder joints. In order to adjust the microstructure of solder, the oxides are always added into $\mathrm{Sn}$-Bi solder. Liu et al. [23] investigated the influence of $\mathrm{Y}_{2} \mathrm{O}_{3}$ on the micro- structure of Sn-58Bi solder. They demonstrated that the morphology of $\mathrm{Sn}-58 \mathrm{Bi}-x \mathrm{Y}_{2} \mathrm{O}_{3}$ composite solder alloy was finer than that of Sn-58Bi solder. The coarsening trend of microstructure of composite solder was inhibited due to the addition of $\mathrm{Y}_{2} \mathrm{O}_{3}$ during aging. Additionally, the thickness of IMC layer of composite solder joints decreased compared with that of Sn-58Bi solder joint. Hu et al. [102] studied the influence of $\mathrm{Sn}-58 \mathrm{Bi}$ incorporation with $0.5 \mathrm{wt} \% \mathrm{Al}_{2} \mathrm{O}_{3}$ nanoparticles on the microstructure during electromigration experiment. It was reported that the thickness of the IMC layer decreased from $2.5 \mu \mathrm{m}$ to $1.27 \mu \mathrm{m}$ under the condition of $288 \mathrm{~h}$ aging at $85^{\circ} \mathrm{C}$, as shown in Figure 21 . Additionally, the growth rate of the IMC layer at the cathode was inhibited and the segregation of Bi-rich layer at the anode was alleviated due to the addition of $\mathrm{Al}_{2} \mathrm{O}_{3}$ nanoparticles under the condition of the current density of $5 \times 10^{3} \mathrm{~A} / \mathrm{cm}^{2}$ at $85^{\circ} \mathrm{C}$. $\mathrm{Zhu}$ et al. [20] also confirmed that the incorporation of $\mathrm{Al}_{2} \mathrm{O}_{3}$ nanoparticles has obvious influence on the microstructure of Sn-58Bi solder, as shown in Figure 22. Moreover, the addition of $\mathrm{CeO}_{2}$ has obvious influence on the microstructure of Sn-58Bi solder [94].

Many researchers tried to improve the properties of Sn-58Bi solder alloy by addition of metal nanoparticles [95-101]. Sun et al. [100] investigated the doping methods of $\mathrm{Ag}$ nanoparticles on the effect of microstructure of $\mathrm{Sn}$ $58 \mathrm{Bi}$ solder. For one way, the Ag nanoparticles were blended with solder alloy powders together directly. For the second way, the nano-Ag particles were doped into the Sn-58Bi solder by the method of sufficient mechanical agitation. It was found that formation of needle-sharped $\mathrm{Ag}_{3} \mathrm{Sn}$ only occurred in the $\mathrm{Sn}-58 \mathrm{Bi}+0.4 \mathrm{Ag}$ composite solder joints, which was associated with uniformly distributed during preparing process, as shown in Figure 23.

Moreover, the novel carbon-based nanometer materials, such as CNTs and graphene, are also selected to adjust the Sn-Bi solders. Lee et al. $[35,61]$ investigated the influence of Sn-decorated multiwalled carbon nanotube (MWCNT) nanoparticles and Ag-decorated MWCNT on the transformation of microstructure of Sn-58Bi solder. They demonstrated that the IMC thickness of composite solder joints was inhibited because of the doping of Sn-MWCNT nanoparticles and the best addition was $0.1 \mathrm{wt} \%$ considering the mechanical properties of solder joints. Additionally, they also demonstrated that the doping of Ag-MWCNTs was effective to suppress the growth of IMC thickness of Sn-58Bi solder joint [35]. Similar phenomenon was also observed in the $\mathrm{Sn}$-58Bi solder with the incorporation of Ni-coated CNTs [103] and $\mathrm{Cu}$-coated CNTs [104]. Ma and Wu [105] reported that the thickness of total IMC layers decreased by $56.31 \%$ compared with the plain Sn5-8Bi-0.7Zn solder joint when the doping of GNSs was $0.114 \mathrm{wt} \%$. In addition, the suppress effect of the IMC was observed by the other researchers due to the doping of GNSs $[36,38,106]$ and epoxy $[59,60]$ into Sn-Bi solder.

3.2.3. Mechanical Properties. The investigation proved that the shear force of $\mathrm{Sn}-58 \mathrm{Bi}-1 \mathrm{wt} \% \mathrm{Y}_{2} \mathrm{O}_{3}$ solder increased by $45 \%$ relative to the $\mathrm{Sn}-58 \mathrm{Bi}$ solder [23]. Hu et al. [102] proved that the doping of $\mathrm{Al}_{2} \mathrm{O}_{3}$ nanoparticles was beneficial for the 


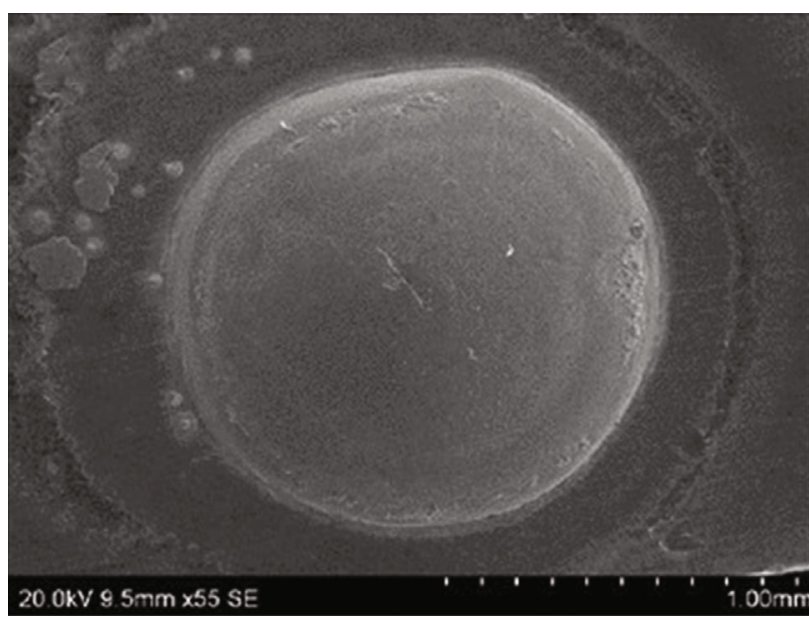

(a)

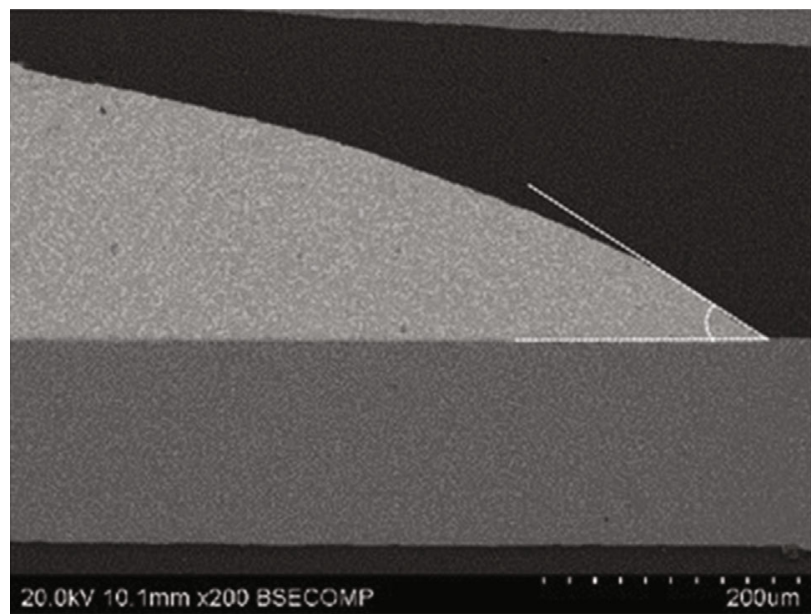

(c)

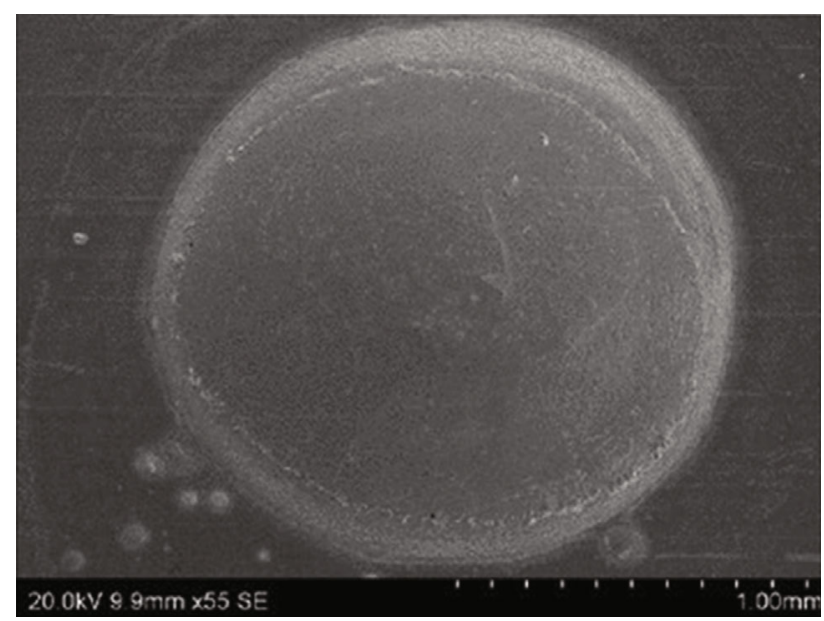

(b)

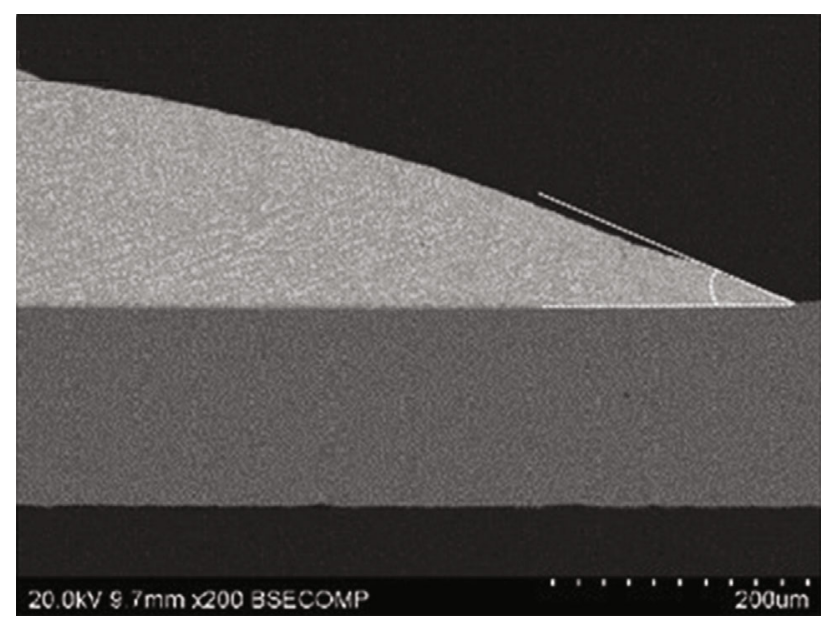

(d)

Figure 20: The SEM pictures of (a, c) plain Sn-Bi-Ag/Cu and (b, d) Sn-Bi-Ag-0.5Ni/Cu composite solder joints [95].

improvement of the shear strength of Sn-58Bi composite solder. Specifically speaking, the shear strength of $\mathrm{Sn}-58 \mathrm{Bi}-$ $0.5 \mathrm{wt} \% \mathrm{Al}_{2} \mathrm{O}_{3}$ composite solder increased by $3.5 \%$ and $2.4 \%$, respectively, with the aging condition of $48 \mathrm{~h}$ and $288 \mathrm{~h}$ at $85^{\circ} \mathrm{C}$ compared with the plain solder. Yang et al. [107] also proved that the electromigration reliability improved for $\mathrm{Cu} / \mathrm{Sn}-58 \mathrm{Bi}-0.5 \mathrm{Al}_{2} \mathrm{O}_{3} / \mathrm{Cu}$ compared with $\mathrm{Cu} / \mathrm{Sn}-58 \mathrm{Bi} / \mathrm{Cu}$ solder joint with the current density of $0.6 \times 10^{4} \mathrm{~A} / \mathrm{cm}^{2}$ at room temperature. Moreover, Zhu et al. [20] pointed out that the UTS of $\mathrm{Sn}-58 \mathrm{Bi}-0.5 \mathrm{Al}_{2} \mathrm{O}_{3}$ composite solder increased by $22 \%$ compared with plain solder, as shown in Figure 24. However, the UTS of Sn-58Bi-1.0 $\mathrm{Al}_{2} \mathrm{O}_{3}$ composite solder decreased due to the formation of fishbone morphology and the accumulation of $\mathrm{Al}_{2} \mathrm{O}_{3}$ nanoparticles. Yang et al. [22] studied the influence of addition of $\mathrm{BaTiO}_{3}$ nanoparticles on the mechanical properties of $\mathrm{Sn}-58 \mathrm{Bi}$. They demonstrated that the UTS of $\mathrm{Sn}-58 \mathrm{Bi}-1 \% \mathrm{BaTiO}_{3}$ increased significantly compared with the plain $\mathrm{Sn}-58 \mathrm{Bi}$ solder, with the values of $59.1 \mathrm{MPa}$ and $44.7 \mathrm{MPa}$, respectively.

Additionally, the metal nanoparticles are always added to enhance the mechanical properties of Sn-58Bi solder. Jiang et al. [97] demonstrated that the improvement of the mechanical properties with the doping of $\mathrm{Ti}$ nanoparticles was associated with the refinement of grains, which attributed to the nucleation effect of nanoparticles. Gain and Zhang [95] pointed out that the microhardness of Sn-Bi$\mathrm{Ag}-0.5 \mathrm{Ni}$ solder increased compared with that of the plain Sn-Bi-Ag solder. Moreover, the $\mathrm{Cu}_{6} \mathrm{Sn}_{5}$ [98] and $\mathrm{CuZnAl}$ [101] are beneficial in the improvement of mechanical properties of Sn-58Bi solder joints.

In recent years, with the appearance of CNTs and graphene, some investigations had been carried out to modify the Sn-Bi solders by the addition of CNTs and graphene [35, 36, 38, 61, 103-106, 108, 109]. Billah and Chen [104] researched the influence of $\mathrm{Cu}$-coated MWCNTs on the mechanical properties of $70 \mathrm{Sn}-30 \mathrm{Bi}$ solder. It was found that the tensile strength of composite solder was proportional to the doping of MWCNTs, which increased by $47.6 \%$ when the addition of MWCNTs was $3 \mathrm{wt} \%$. Lee et al. $[35,61]$ investigated the influence of Sn-decorated MWCNT nanoparticles and Ag-decorated MWCNT on the mechanical properties of Sn-58Bi solder. They found that the doping of Sn-decorated MWCNT nanoparticles could improve the mechanical properties and the optimum addition was $0.1 \mathrm{wt} \%$ [61] and the 


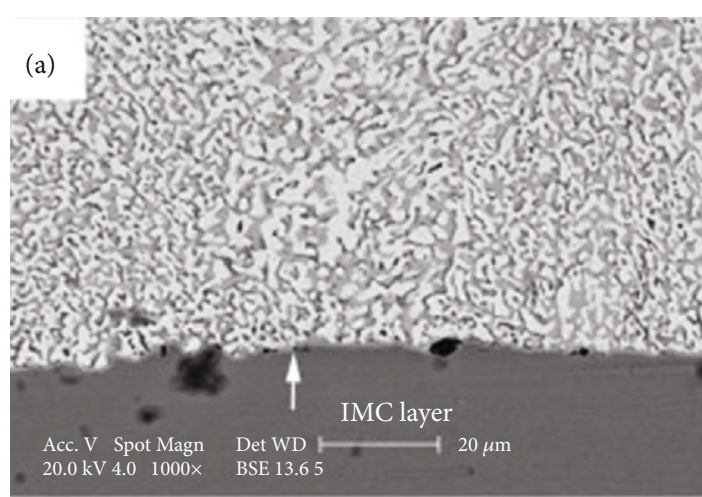

(a)

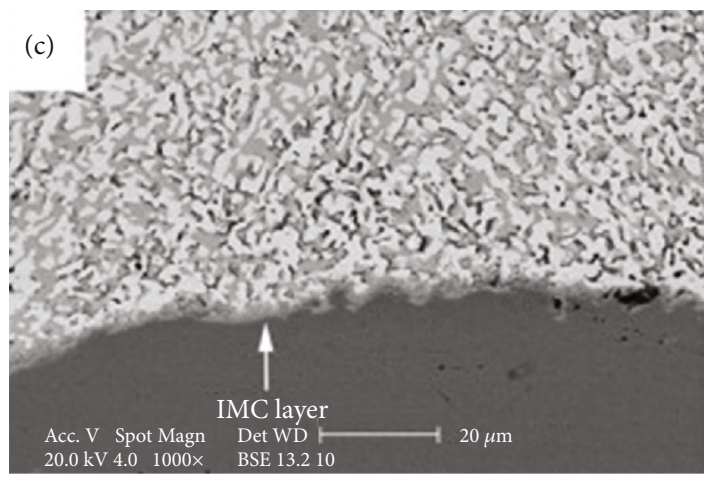

(c)

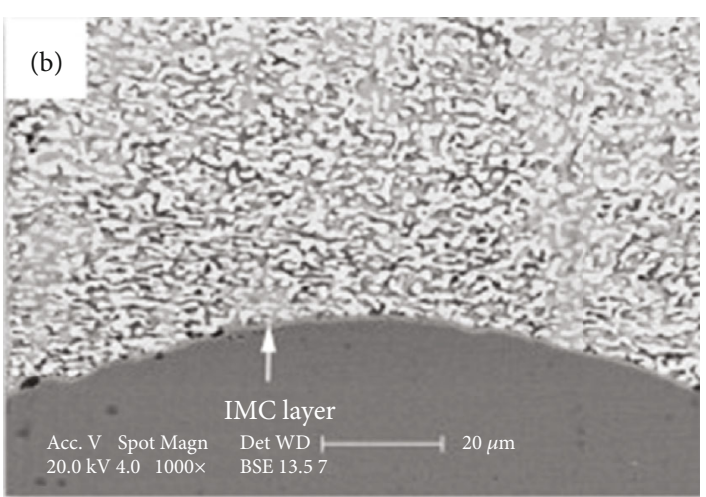

(b)

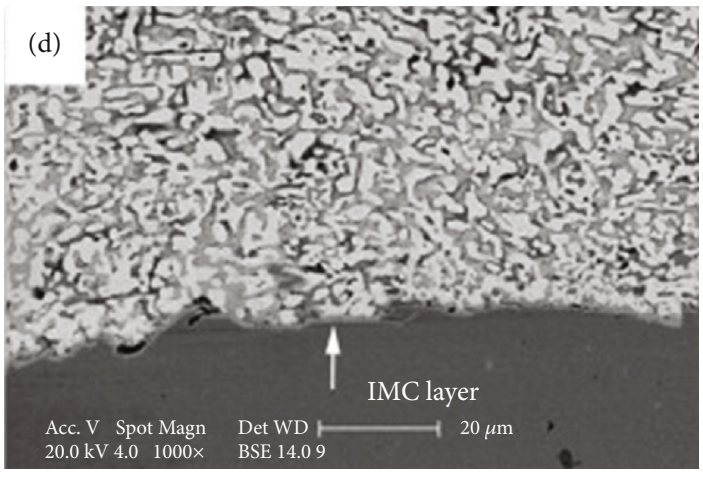

(d)

Figure 21: The SEM images of interface microstructure of solder joints: (a, b) Sn-58Bi/Cu and Sn-58Bi-0.5 $\mathrm{Al}_{2} \mathrm{O}_{3} / \mathrm{Cu}$ solder joints annealed for $48 \mathrm{~h}$ at $85^{\circ} \mathrm{C}$ and $(\mathrm{c}, \mathrm{d}) \mathrm{Sn}-58 \mathrm{Bi} / \mathrm{Cu}$ and $\mathrm{Sn}-58 \mathrm{Bi}-0.5 \mathrm{Al}_{2} \mathrm{O}_{3} / \mathrm{Cu}$ solder joints annealed for $288 \mathrm{~h}$ at $85^{\circ} \mathrm{C}$ [102].

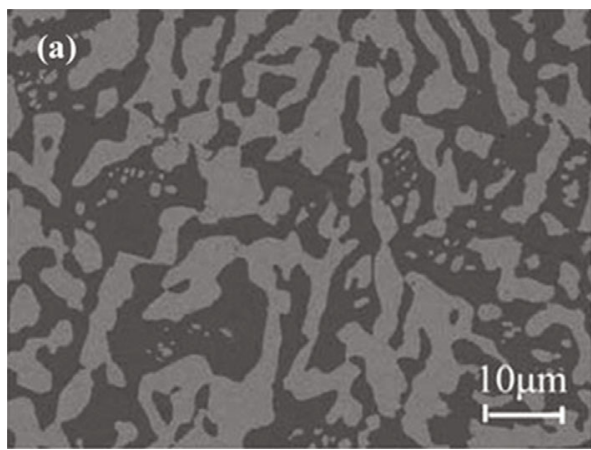

(a)

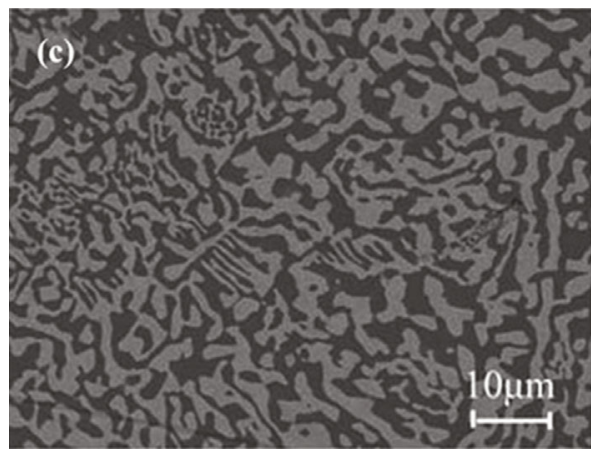

(c)

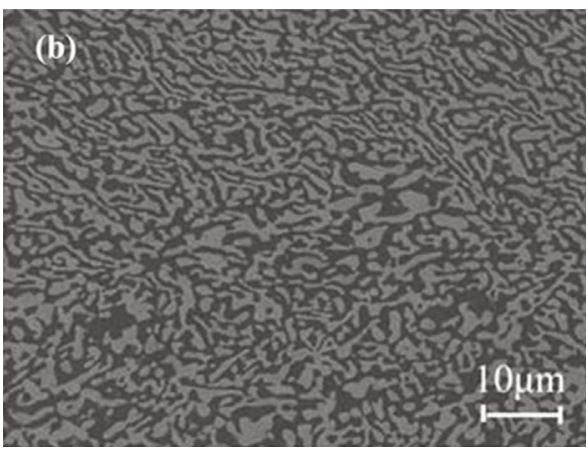

(b)

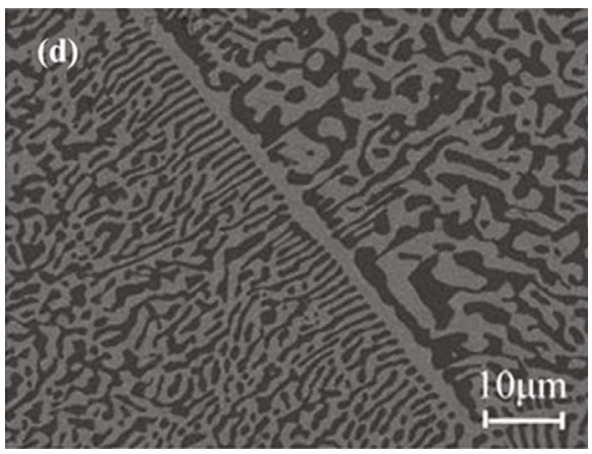

(d)

FIgURE 22: The morphology of solder alloys: (a) Sn-58Bi, (b) Sn-58Bi+0.5 $\mathrm{Al}_{2} \mathrm{O}_{3}$, (c) $\mathrm{Sn}-58 \mathrm{Bi}+1.0 \mathrm{Al}_{2} \mathrm{O}_{3}$, and (d) $\mathrm{Sn}-58 \mathrm{Bi}+1.5 \mathrm{Al}{ }_{2} \mathrm{O}_{3}[20]$. 


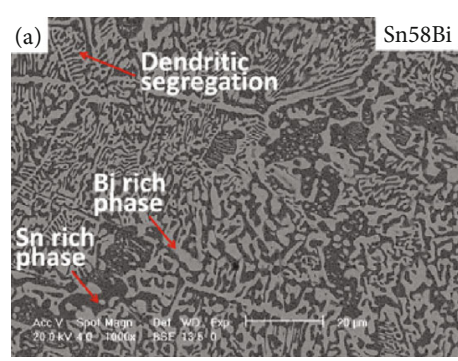

(a)

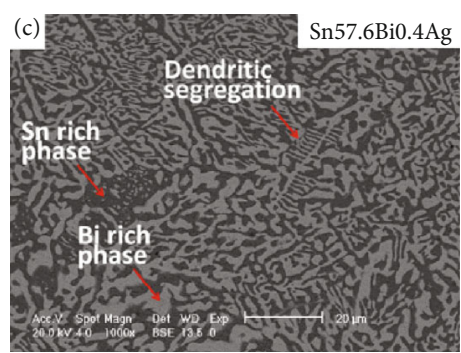

(c)

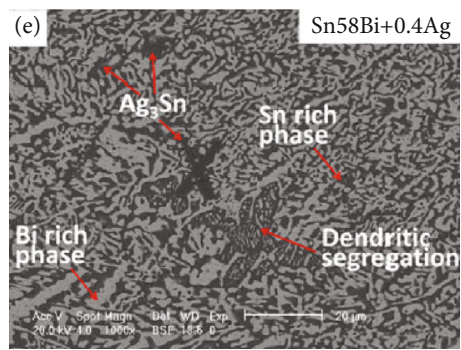

(e)

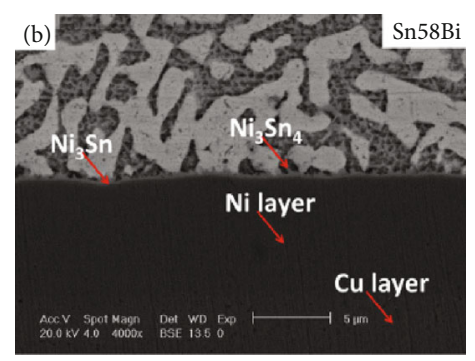

(b)

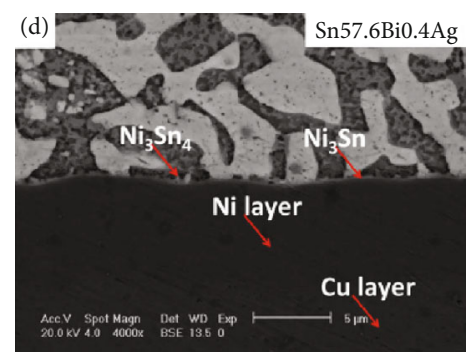

(d)

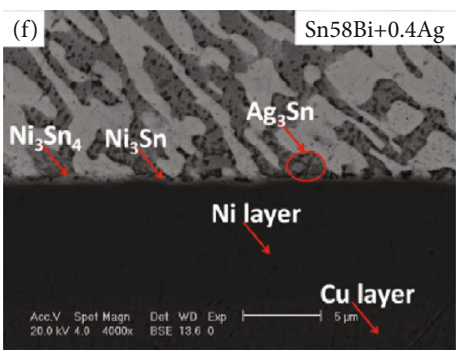

(f)

Figure 23: The SEM images of solder joints: (a, b) Sn-58Bi/Cu, (c, d) Sn-57.6-Bi-0.4Ag/Cu, and (e, f) Sn-58Bi+0.4Ag/Cu [100].

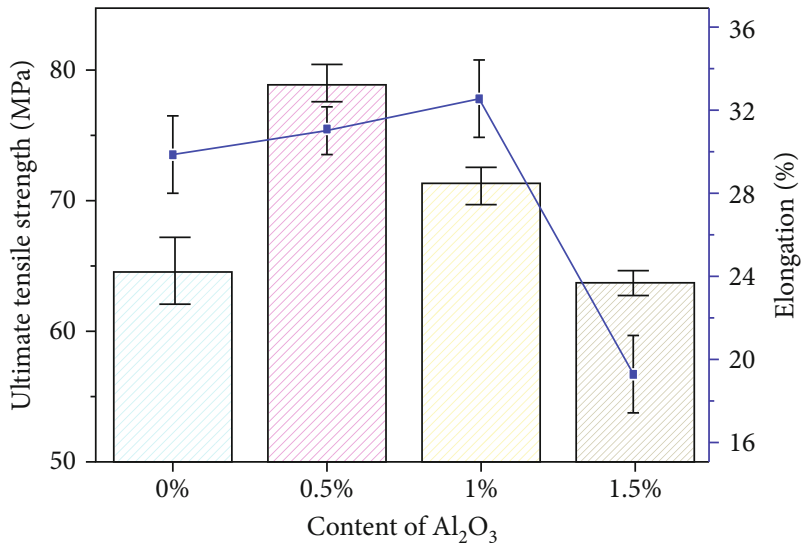

FIGURE 24: The evolution of elongation and UTS of solder samples [20].

fracture energy and shear strength increased by $80 \%$ and $16 \%$, respectively, when the addition of Ag-MWCNTs was $0.05 \mathrm{wt} \%$ [35]. He et al. [108] demonstrated that the bending strength of $\mathrm{Sn}-58 \mathrm{Bi}-0.03 \mathrm{CNT}$ s composite solder increased by $10.5 \%$ compared with the plain Sn-58Bi solder. Additionally, the toughness of $\mathrm{Sn}-58 \mathrm{Bi}-0.03 \mathrm{CNT}$ s composite solder increased by $48.9 \%$ than that of plain solder. In addition, Sun et al. [36] also pointed out that the addition of CNTs

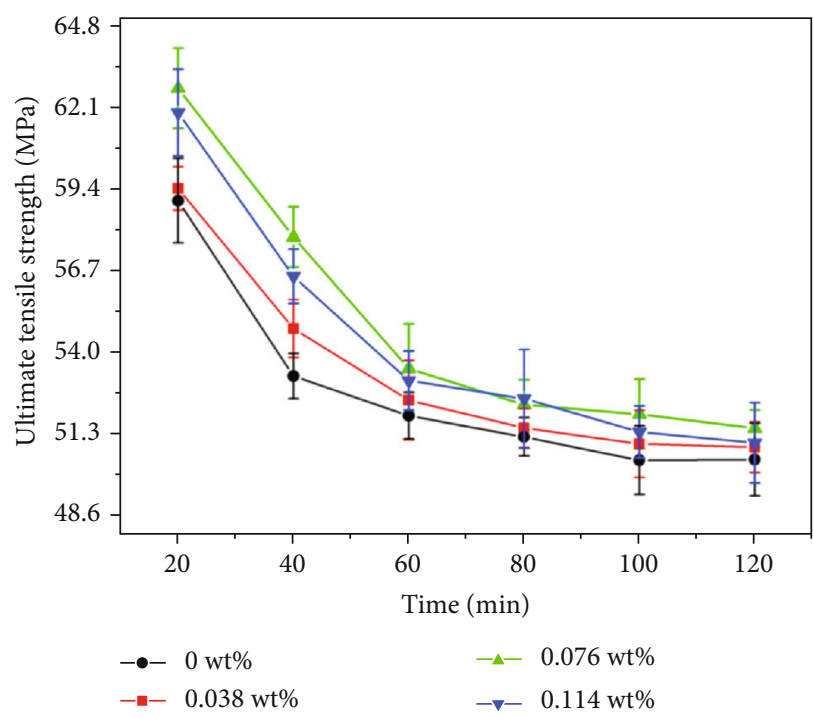

FIGURE 25: The UTS of plain solder joint and composite solder joints after aging for different times [105].

and Ni-CNTs displayed positive influence in the enhancement of mechanical properties of $\mathrm{Sn}-57.6-\mathrm{Bi}-0.4 \mathrm{Ag}$ composite solder joints. 


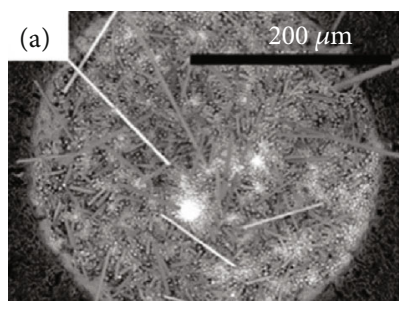

(a)

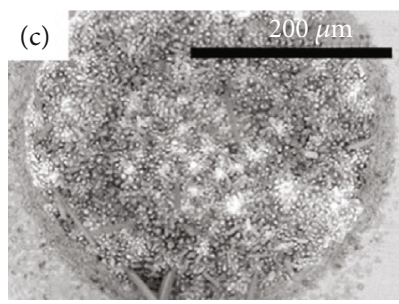

(c)

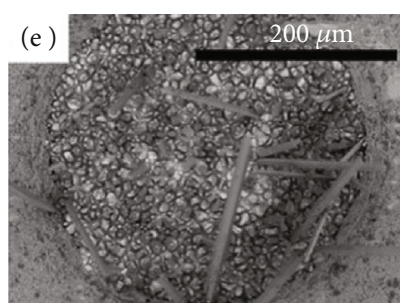

(e)

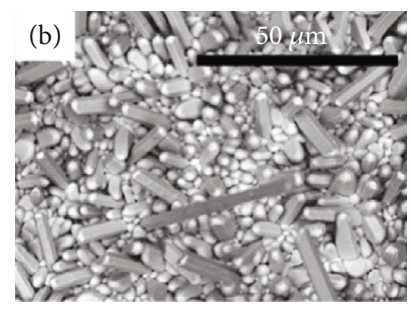

(b)

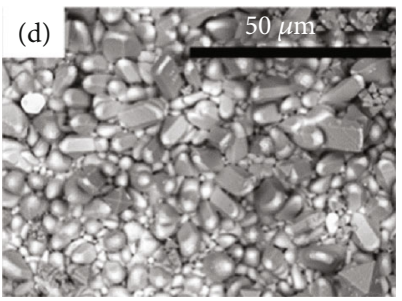

(d)

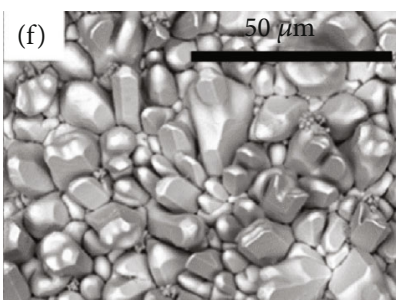

(f)

Figure 26: The evolution of the interfacial $\mathrm{Cu}_{6} \mathrm{Sn}_{5}$ of $\mathrm{Sn}-0.7 \mathrm{Cu} / \mathrm{Cu}$ with different reflow cycles. The 1 st reflow cycle $(\mathrm{a}, \mathrm{b})$, the $2 \mathrm{rd}$ reflow cycle (c, d), and the 6th reflow cycle (e, f) [110].

$\mathrm{Ma}$ and $\mathrm{Wu}[105]$ investigated the influence of the incorporation of GNS on the evolution of mechanical properties of Sn-58Bi-0.7Zn solder. They pointed out that the Sn-58Bi$0.7 \mathrm{Zn}-0.076 \mathrm{wt} \%$ GNS composite solder displays the highest UTS among all samples in the same aging time, as shown in Figure 25. The decrease in UTS with an increase in ageing time is likely attributed to the coarsening of IMC [105]. Additionally, the adsorption effect of nanoparticles on IMC grains could suppress the growth of IMC layer, which is beneficial for the improvement of UTS of composite solder joints [105]. Meanwhile, Yang et al. [106] pointed out the UTS of $\mathrm{Sn}-\mathrm{Bi}+0.07 \mathrm{wt} \%$ composite solder had no obvious change compared with the plain solder, and the elongation and creep properties show a great improvement. Moreover, the improvement phenomenon of mechanical properties is observed by the other researchers due to the doping of GNSs $[36,38,106]$ and epoxy $[59,60]$ into Sn-Bi solder.

\subsection{Other Sn-Based Lead-Free Solder}

3.3.1. Microstructure of Solder Joints. Sn-Cu, Sn-Zn, and Sn$\mathrm{Ag}$ solders are also investigated worldwide to replace $\mathrm{Sn}-\mathrm{Pb}$ solder. Mohd Salleh et al. [50] demonstrated that the doping of $\mathrm{TiO}_{2}$ could have resulted in the refinement of microstructure of $\mathrm{Sn}-0.7 \mathrm{wt} \% \mathrm{Cu}-0.05 \mathrm{wt} \% \mathrm{Ni}$ solder by the fabricate process of microwave sintered and the homogeneous $(\mathrm{Cu}$, $\mathrm{Ni})_{6} \mathrm{Sn}_{5}$ intermetallics appear in the grains of particles. Moreover, they also investigated the evolution of $\mathrm{Cu}_{6} \mathrm{Sn}_{5}$ IMC of
$\mathrm{TiO}_{2}$ additive $\mathrm{Sn}-0.7 \mathrm{Cu}$ composite solder after different reflow cycles [110]. It was confirmed that the incorporation of $\mathrm{TiO}_{2}$ nanometer particles could suppress the growth of $\mathrm{Cu}_{6} \mathrm{Sn}_{5}$, which was associated with the inhibiting effect as shown in Figures 26 and 27, respectively. It can be seen that the $\mathrm{Cu}_{6} \mathrm{Sn}_{5}$ of additive- $\mathrm{TiO}_{2} \mathrm{Sn}-0.7 \mathrm{Cu} / \mathrm{Cu}$ composite solder joints became more faced and flat compared with the plain $\mathrm{Sn}-0.7 \mathrm{Cu} / \mathrm{Cu}$ solder joints. The change of average thickness of the interfacial $\mathrm{Cu}_{6} \mathrm{Sn}_{5}$ is shown in Figure 28. And the refinement of $\mathrm{Cu}_{6} \mathrm{Sn}_{5}$ was associated with the inhibition effect between the $\mathrm{Cu}$ substrate and the molten solder due to the addition of $\mathrm{TiO}_{2}$. Furthermore, they studied the influence of $\mathrm{Ni}$ and $\mathrm{TiO}_{2}$ separate doping and combined incorporation on the evolution of microstructure of $\mathrm{Sn}-0.7 \mathrm{Cu} / \mathrm{Cu}$ solder joint with different aging time systematically [111]. It was found that scallop-shaped $\mathrm{Cu}_{6} \mathrm{Sn}_{5}$ and planar $\mathrm{Cu}_{3} \mathrm{Sn}$ were formed between the $\mathrm{Cu}$ substrate and solder matrix for $\mathrm{Sn} 0.7 \mathrm{Cu} / \mathrm{Cu}$ solder joint, as shown in Figure 29. Then, planar scalloped $\mathrm{Cu}_{6} \mathrm{Sn}_{5}$ layer formed due to the addition of $\mathrm{TiO}_{2}$ into the $\mathrm{Sn}-0.7 \mathrm{Cu}$ solder. Moreover, the total thickness of the IMC layer for both the $\mathrm{Sn}-0.7 \mathrm{Cu}-\mathrm{TiO}_{2} / \mathrm{Cu}$ and $\mathrm{Sn}-$ $0.7 \mathrm{Cu}-0.05 \mathrm{Ni}-\mathrm{TiO}_{2} / \mathrm{Cu}$ composite solder joints decreased by $10-40 \%$ with the increase of aging time, as displayed in Figure 30. In addition, the inhibiting effect of IMC for the composite solder is observed due to the incorporation of $\mathrm{Si}_{3} \mathrm{~N}_{4}$ [112] and $\mathrm{Cu}$ nanometer particles [113].

$\mathrm{Sn}$-Cu eutectic solder alloy was also considered one of the potential candidates to replace the traditional $\mathrm{Sn}-\mathrm{Pb}$ solder 


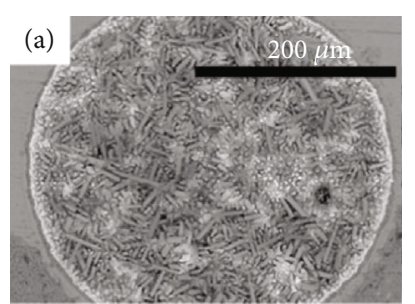

(a)

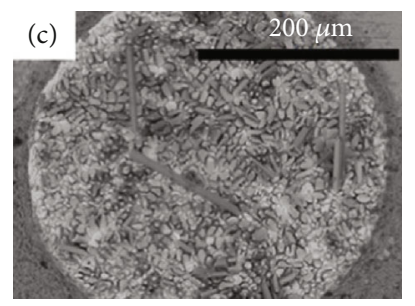

(c)

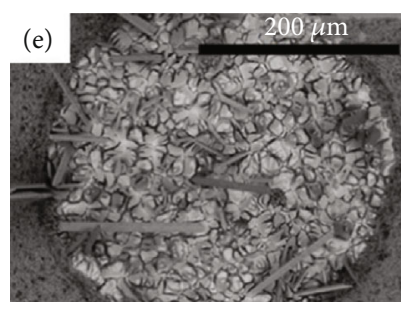

(e)

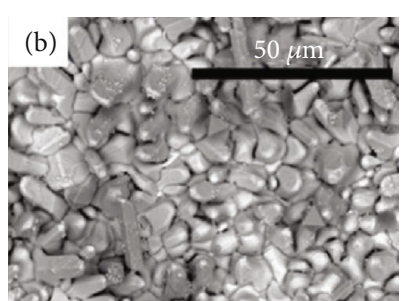

(b)

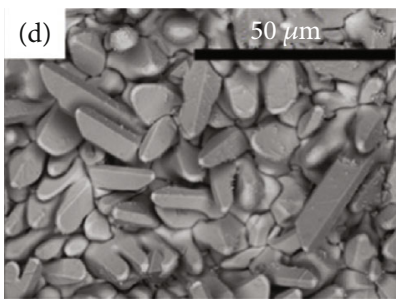

(d)

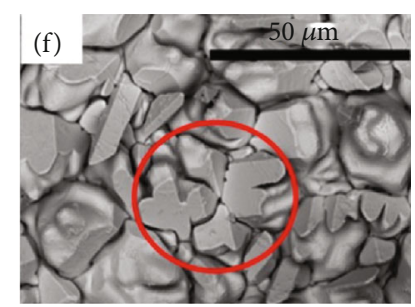

(f)

Figure 27: The evolution of the interfacial $\mathrm{Cu}_{6} \mathrm{Sn}_{5}$ of $\mathrm{Sn}-0.7 \mathrm{Cu}+\mathrm{TiO}_{2} / \mathrm{Cu}$ with different reflow cycles. The 1 st reflow cycle (a, b), the $2 \mathrm{rd}$ reflow cycle (c, d), and the 6th reflow cycle $(e, f)[110]$.

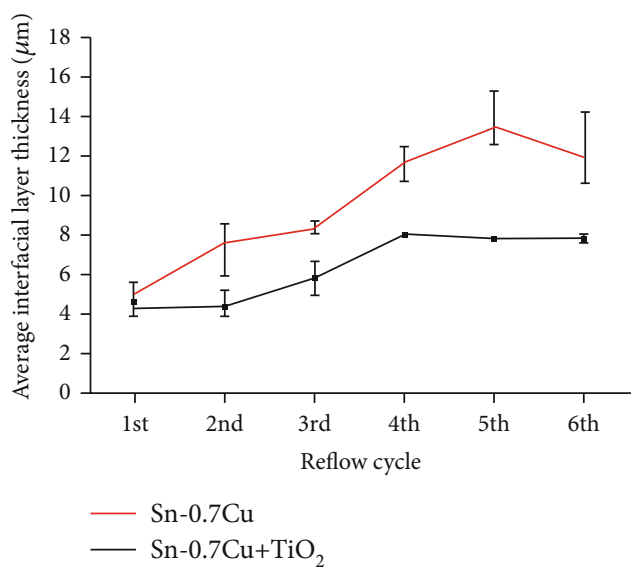

Figure 28: The thickness of interfacial layer of $\mathrm{Sn}-0.7 \mathrm{Cu} / \mathrm{Cu}$ solder joints and $\mathrm{Sn}-0.7 \mathrm{Cu}+\mathrm{TiO}_{2} / \mathrm{Cu}$ composite solder joints with various reflows [110].

alloy because of the virtue of low-cost and good comprehensive properties. Consequently, the $\mathrm{Sn}$-Cu composite solders were fabricated by the addition of nanometer particles. It had been demonstrated that the incorporation of nanometer particles of $\mathrm{Ni}$ [114, 115], $\mathrm{Ag}$ [116], $\mathrm{ZrO}_{2}$ [28], $\mathrm{Al}_{2} \mathrm{O}_{3}$ [117], and $\mathrm{TiO}_{2}$ [24] could alter the microstructure of solder then resulted in the change of mechanical properties.
3.3.2. Mechanical Properties. Mohd Salleh et al. [110] investigated the transformation of shear strength of $\mathrm{TiO}_{2}$ additive $\mathrm{Sn}-0.7 \mathrm{Cu}$ composite solder after different reflow cycles. They pointed out that the addition of $\mathrm{TiO}_{2}$ enhanced the shear strength of $\mathrm{Sn}-0.7 \mathrm{Cu}-\mathrm{TiO}_{2} / \mathrm{Cu}$ composite solder joint for each reflow cycle as compared with that of $\mathrm{Sn}-0.7 \mathrm{Cu} / \mathrm{Cu}$ solder joint, and the shear strength of solder joint without the addition of $\mathrm{TiO}_{2}$ was sensitive to the number of reflow cycle, while there was no obvious change of the shear strength for the additive- $\mathrm{TiO}_{2}$ composite solder joint with the increase number of reflow cycle, as shown in Figure 31. Additionally, they confirmed that the $\mathrm{Sn}-0.7 \mathrm{Cu}-0.05 \mathrm{Ni}+\mathrm{TiO}_{2} / \mathrm{Cu}$ solder joint had the optimum shear strength among the Sn$0.7 \mathrm{Cu} / \mathrm{Cu}, \mathrm{Sn}-0.7 \mathrm{Cu}+\mathrm{TiO}_{2} / \mathrm{Cu}, \mathrm{Sn}-0.7 \mathrm{Cu}-0.05 \mathrm{Ni} / \mathrm{Cu}$, and $\mathrm{Sn}-0.7 \mathrm{Cu}-0.05 \mathrm{Ni}+\mathrm{TiO}_{2} / \mathrm{Cu}$ solder joints, as displayed in Figure 32, which was associated with inhibition of the $\mathrm{Cu}_{3} \mathrm{Sn}$ and the total thickness of IMC layer [111]. Tsao et al. [118] also demonstrated that the UTS of $\mathrm{Sn}-0.7 \mathrm{Cu}-x \mathrm{TiO}_{2}$ composite solder increased because of the addition of $\mathrm{TiO}_{2}$, which attributes to the formation of fine and uniform microstructure.

In addition, some $\mathrm{Sn}-\mathrm{Cu}$ based composite solder alloys were fabricated by the addition of nanometer particles [24, $28,114,115,117]$. Gain et al. [115] demonstrated that the shear strength of Sn-9Zn and Sn-8Zn-3Bi increased because of the doping of $\mathrm{Ni}$ nanometer particles and the evolution of mechanical properties of the above-mentioned composite 


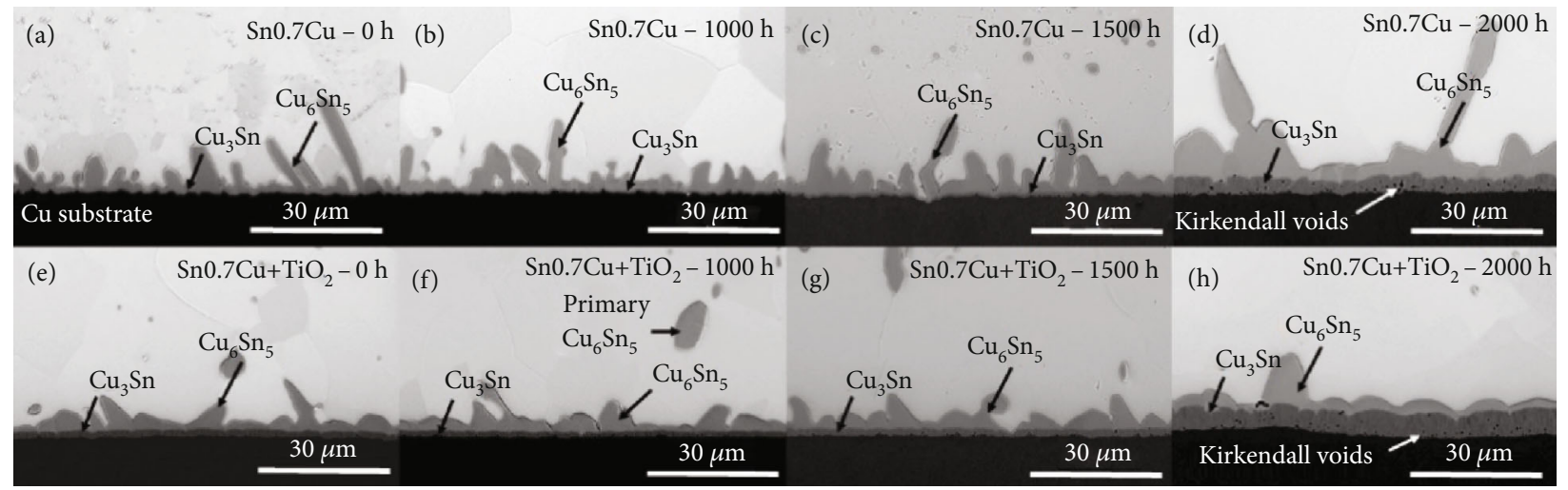

FIgURE 29: Evolution of microstructure of the interfacial IMC of $\mathrm{Cu}_{6} \mathrm{Sn}_{5}$ and $\mathrm{Cu}_{3} \mathrm{Sn}$ in aging Sn-0.7Cu/Cu after (a) $0 \mathrm{~h},(\mathrm{~b}) 1000 \mathrm{~h},(\mathrm{c}) 1500 \mathrm{~h}$, and (d) $2000 \mathrm{~h}$ and $\mathrm{Sn}-0.7 \mathrm{Cu}+\mathrm{TiO}_{2} / \mathrm{Cu}$ composite solder joint after (e) $0 \mathrm{~h}$, (f) $1000 \mathrm{~h}$, (g) $1500 \mathrm{~h}$, and (h) $2000 \mathrm{~h} \mathrm{[111].}$

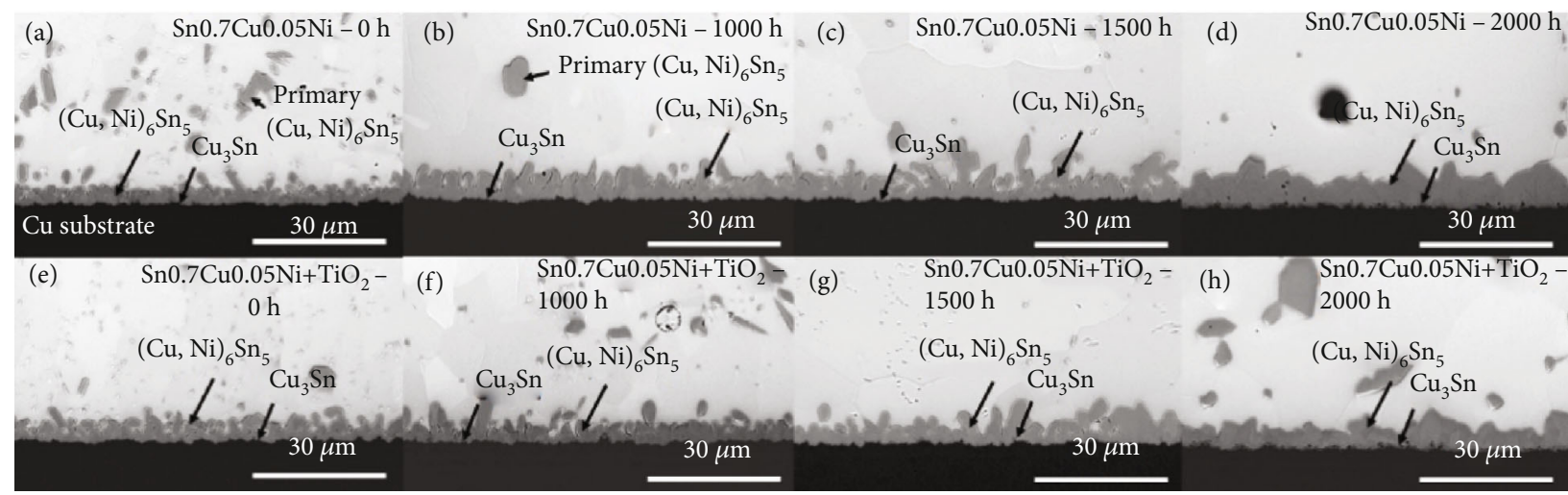

Figure 30: Evolution of microstructure of the interfacial IMC of $(\mathrm{Cu}, \mathrm{Ni})_{6} \mathrm{Sn}_{5}$ and $\mathrm{Cu}_{3} \mathrm{Sn}$ in aging $\mathrm{Sn}-0.7 \mathrm{Cu}-0.05 \mathrm{Ni} / \mathrm{Cu}$ after (a) $0 \mathrm{~h},(\mathrm{~b})$ $1000 \mathrm{~h},(\mathrm{c}) 1500 \mathrm{~h}$, and (d) $2000 \mathrm{~h}$ and $\mathrm{Sn} 0.7 \mathrm{Cu}-0.05 \mathrm{Ni}+\mathrm{TiO}_{2} / \mathrm{Cu}$ composite solder joint after (e) $0 \mathrm{~h},(\mathrm{f}) 1000 \mathrm{~h},(\mathrm{~g}) 1500 \mathrm{~h}$, and $(\mathrm{h})$ $2000 \mathrm{~h} \mathrm{[111].}$

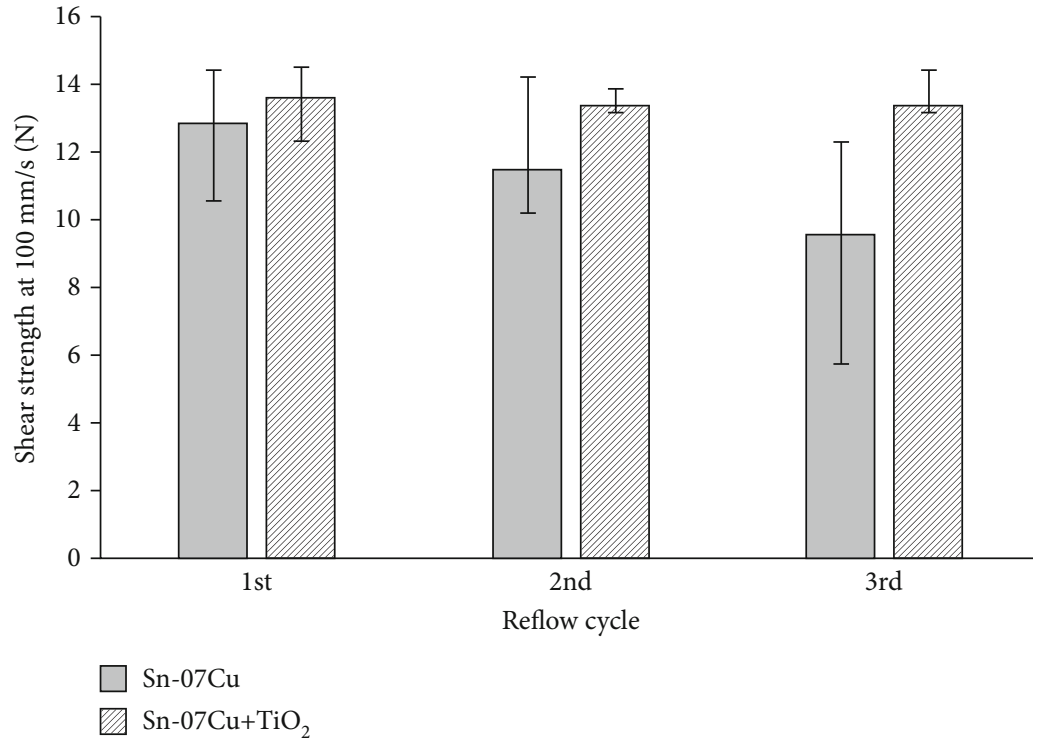

Figure 31: (a) Shear force of $\mathrm{Sn}-0.7 \mathrm{Cu}$ and $\mathrm{Sn}-0.7 \mathrm{Cu}+\mathrm{TiO}_{2}$ composite solder joint with multiple reflow cycle at the testing speed of $100 \mathrm{~mm} / \mathrm{s}[110]$. 


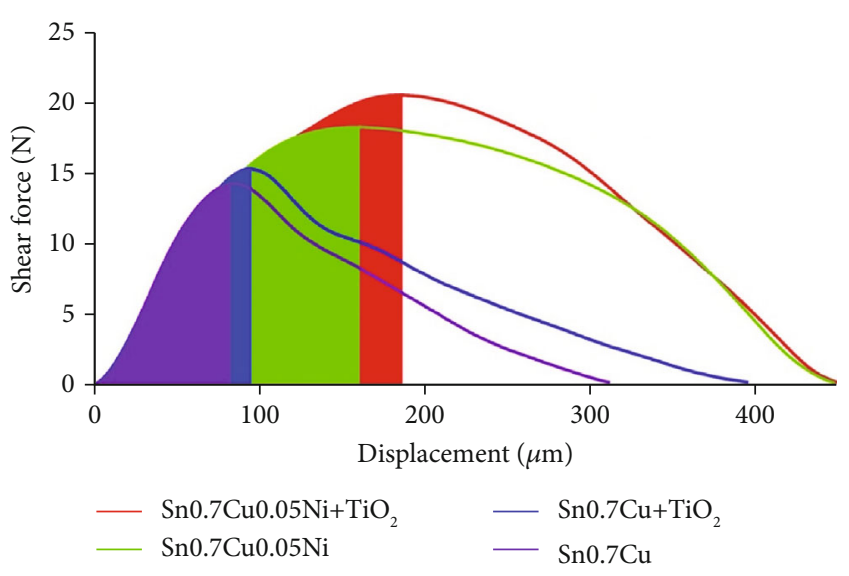

(a)

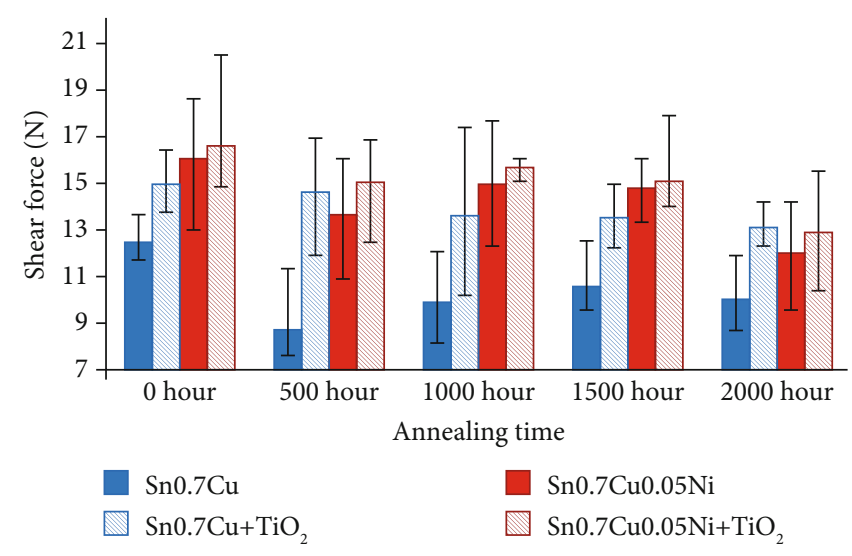

(b)

Figure 32: The evolution of shear strength of different types solder joints with different aging time. (a) Graph of shear strength versus displacement and (b) graph of shear strength versus aging time [111].

was caused by the refinement of microstructure. Xing et al. [117] confirmed that both of the tensile strength and microhardness of $\mathrm{Sn}-9 \mathrm{Zn}-x \mathrm{Al}_{2} \mathrm{O}_{3}$ composite solder alloys increased with the increase of $\mathrm{Al}_{2} \mathrm{O}_{3}$ nanoparticle content. Additionally, the improvement in mechanical properties for $\mathrm{Sn}-\mathrm{Zn}$ solder alloy could be achieved by the addition of nanoparticles of $\mathrm{ZrO}_{2}$ [28] and $\mathrm{TiO}_{2}$ [24].

\section{Summary and Conclusions}

As mentioned above, we presented a laconic summary of the transformation law of wettability, microstructure morphology, and mechanical properties of Sn-based lead-free composite solder alloys after the addition of nanometer particles. The relevant experimental results of these investigations demonstrated that the wettability and mechanical properties of Snbased lead-free composite solder alloys improved due to the addition of nanometer particles, which is associated with the refinement of microstructure. And the refinement of microstructure of Sn-based lead-free composite solder alloys is mainly attributed to the nucleation effect of the nanometer particles. At present, most of the investigations about the effect of the addition of nanometer particles on the evolution of wettability, microstructure, and mechanical properties are qualitatively evaluated and it is necessary to expound the internal evolution mechanism of the properties of composite solder alloy by the addition of nanometer particles. Moreover, it is necessary to establish the relationship between the additions and properties of composite solder alloy quantitatively by multiscale characterization.

What is more, the reliability of Sn-based lead-free composite solder joints in service environment should be evaluated by means of laboratory simulation, such as drop impact, thermal cycle aging, and corrosion testing. To further improve the properties of Sn-based lead-free composite solder joint, the research can be carried out in the following aspects:

(1) At present, Sn-based lead-free composite solders are mainly fabricated by mechanical mixing of the solder particles and nanoparticles. It is necessary to explore new preparation methods to improve the properties of Sn-based lead-free composite solders. The high-throughput computation and high-throughput experimentation based on a materials genome perspective should be applied to fabricate composite solders with excellent properties

(2) It has been proven that the coupling addition of rare earth (RE) and nanoparticles is effective to improve the properties of lead-free solders. Consequently, the effect of combined doping of RE and nanoparticles on the properties of lead-free solders should be investigated further

(3) The reliability of Sn-based lead-free composite solders should be evaluated at cryogenic temperatures and radiation conditions due to the space exploration

\section{Conflicts of Interest}

The authors declare that they have no conflicts of interest.

\section{Acknowledgments}

This research was funded by Natural Science Foundation Youth Science Fund Project and Excellent Youth Project of Henan (Nos. 202300410272 and 202300410268), the China Ministry of Education's industry-academy cooperation in collaboration with the education project (201901078004 and 201901078022), Open Fund of National Joint Engineering Research Center for Abrasion Control and Molding of Metal Materials (No. HKDNM2019020), the National Natural Science Foundation of China (51705151 and 52071165), the China Postdoctoral Science Foundation (2019M662011), Open Fund of State Key Laboratory of Advanced Brazing Filler Metals and Technology (SKLABFMT201901), Open Fund of State Key Laboratory of Advanced Welding and Joining (AWJ-21M11), and Key Technology Needs of Henan Province Unveiled and Solved Project (191110111000). 


\section{References}

[1] S. Li and Y. F. Yan, "Intermetallic growth study at Sn-3.0Ag$0.5 \mathrm{Cu} / \mathrm{Cu}$ solder joint interface during different thermal conditions," Journal of Materials Science: Materials in Electronics, vol. 26, no. 12, pp. 9470-9477, 2015.

[2] V. Srivastava and M. Gupta, "Experimental assessment of self-healing nature in aluminum-based smart composites with NiTi wires and solder alloy as healing agents through Taguchi approach," Journal of Intelligent Material Systems and Structures, vol. 31, no. 18, pp. 2101-2116, 2020.

[3] S. Li, X. Wang, Z. Liu et al., "Corrosion behavior of Sn-based lead-free solder alloys: a review," Journal of Materials Science: Materials in Electronics, vol. 31, no. 12, pp. 9076-9090, 2020.

[4] N. W. B. Subri, M. Sarraf, B. Nasiri-Tabrizi et al., "Corrosion insight of iron and bismuth added $\mathrm{Sn}-1 \mathrm{Ag}-0.5 \mathrm{Cu}$ lead-free solder alloy," Corrosion Engineering, Science and Technology, vol. 55, no. 1, pp. 35-47, 2020.

[5] V. Srivastava and M. Gupta, "Experimental assessment of self-healing characteristics in AA2014matrix with nitinol wire and solder alloy as healing agents," Materials Research Express, vol. 6, no. 8, article 085704, 2019.

[6] X. Zhong, L. Chen, B. Medgyes, Z. Zhang, S. Gao, and L. Jakab, "Electrochemical migration of $\mathrm{Sn}$ and $\mathrm{Sn}$ solder alloys: a review," RSC Advances, vol. 7, no. 45, pp. 2818628206, 2017.

[7] B. Liao, Z. Chen, Q. Qiu, and X. Guo, "Inhibitory effect of cetyltrimethylammonium bromide on the electrochemical migration of tin in thin electrolyte layers containing chloride ions," Corrosion Science, vol. 118, pp. 190-201, 2017.

[8] D. Q. Yu, L. Wang, C. M. L. Wu, and C. M. T. Law, "The formation of nano- $\mathrm{Ag}_{3} \mathrm{Sn}$ particles on the intermetallic compounds during wetting reaction," Journal of Alloys and Compounds, vol. 389, no. 1-2, pp. 153-158, 2005.

[9] A. K. Gain and Y. C. Chan, "The influence of a small amount of $\mathrm{Al}$ and $\mathrm{Ni}$ nano-particles on the microstructure, kinetics and hardness of $\mathrm{Sn}-\mathrm{Ag}-\mathrm{Cu}$ solder on OSP-Cu pads," Intermetallics, vol. 29, pp. 48-55, 2012.

[10] A. A. el-Daly, A. E. Hammad, A. Fawzy, and D. A. Nasrallh, "Microstructure, mechanical properties, and deformation behavior of $\mathrm{Sn}-1.0 \mathrm{Ag}-0.5 \mathrm{Cu}$ solder after $\mathrm{Ni}$ and $\mathrm{Sb}$ additions," Materials \& Design, vol. 43, pp. 40-49, 2013.

[11] Y. Tang, S. M. Luo, W. F. Huang, Y. C. Pan, and G. Y. Li, "Effects of Mn nanoparticles on tensile properties of low-Ag Sn-0.3Ag-0.7Cu-xMn solder alloys and joints," Journal of Alloys and Compounds, vol. 719, pp. 365-375, 2017.

[12] D. Soares, M. Sarmento, D. Barros et al., "The effect of Bi addition on the electrical and microstructural properties of SAC405 soldered structure," Soldering \& Surface Mount Technology, 2020.

[13] Z. L. Ma, S. A. Belyakov, and C. M. Gourlay, "Effects of cobalt on the nucleation and grain refinement of Sn-3Ag-0.5Cu solders," Journal of Alloys and Compounds, vol. 682, pp. 326337, 2016.

[14] F. Gao, T. Takemoto, and H. Nishikawa, "Effects of Co and Ni addition on reactive diffusion between $\mathrm{Sn}-3.5 \mathrm{Ag}$ solder and $\mathrm{Cu}$ during soldering and annealing," Materials Science and Engineering: A, vol. 420, no. 1-2, pp. 39-46, 2006.

[15] M. S. Gumaan, "Chromium improvements on the mechanical performance of a rapidly solidified eutectic $\mathrm{Sn}-\mathrm{Ag}$ alloy," Journal of Materials Science: Materials in Electronics, vol. 31, no. 13, pp. 10731-10737, 2020.
[16] B. Ali, M. F. M. Sabri, I. Jauhari, and N. L. Sukiman, "Impact toughness, hardness and shear strength of Fe and Bi added Sn-1Ag-0.5Cu lead-free solders," Microelectronics Reliability, vol. 63, pp. 224-230, 2016.

[17] W. Yang, Z. Du, S. Yu et al., "The effect of rare earths additions on the microstructure and the corrosion behavior of Sn-0.7Cu-0.075Al solder alloy," Materials, vol. 12, no. 22, p. $3731,2019$.

[18] D. H. Xiao, J. N. Wang, D. Y. Ding, and H. L. Yang, "Effect of rare earth Ce addition on the microstructure and mechanical properties of an $\mathrm{Al}-\mathrm{Cu}-\mathrm{Mg}-\mathrm{Ag}$ alloy," Journal of Alloys and Compounds, vol. 352, no. 1-2, pp. 84-88, 2003.

[19] R. M. Shalaby and H. Elzanaty, "Effect of nano- $\mathrm{Al}_{2} \mathrm{O}_{3}$ particles on the microstructure and mechanical performance of melt-spun process $\mathrm{Sn}-3.5 \mathrm{Ag}$ composite solder," Journal of Materials Science: Materials in Electronics, vol. 31, no. 8, pp. 5907-5913, 2020.

[20] W. Zhu, Y. Ma, X. Li, W. Zhou, and P. Wu, "Effects of $\mathrm{Al}_{2} \mathrm{O}_{3}$ nanoparticles on the microstructure and properties of Sn58Bi solder alloys," Journal of Materials Science: Materials in Electronics, vol. 29, no. 9, pp. 7575-7585, 2018.

[21] S. Tikale and K. N. Prabhu, "Development of low-silver content SAC0307 solder alloy with $\mathrm{Al}_{2} \mathrm{O}_{3}$ nanoparticles," Materials Science and Engineering: A, vol. 787, article 139439, 2020.

[22] L. Yang, J. Dai, Y. Zhang, Y. Jing, J. Ge, and H. Liu, "Influence of $\mathrm{BaTiO}_{3}$ nanoparticle addition on microstructure and mechanical properties of Sn-58Bi solder," Journal of Electronic Materials, vol. 44, no. 7, pp. 2473-2478, 2015.

[23] X. Liu, M. Huang, C. M. L. Wu, and L. Wang, "Effect of $\mathrm{Y}_{2} \mathrm{O}_{3}$ particles on microstructure formation and shear properties of Sn-58Bi solder," Journal of Materials Science: Materials in Electronics, vol. 21, no. 10, pp. 1046-1054, 2010.

[24] A. M. Yassin, H. Y. Zahran, and A. F. Abd El-Rehim, "Effect of $\mathrm{TiO}_{2}$ nanoparticles addition on the thermal, microstructural and room-temperature creep behavior of $\mathrm{Sn}$ - Zn based solder," Journal of Electronic Materials, vol. 47, no. 12, pp. 6984-6994, 2018.

[25] Y. Tang, S. M. Luo, G. Y. Li, Z. Yang, and C. J. Hou, "Ripening growth kinetics of $\mathrm{Cu}_{6} \mathrm{Sn}_{5}$ grains in $\mathrm{Sn}-3.0 \mathrm{Ag}-0.5 \mathrm{Cu}-$ $\mathrm{xTiO}_{2} / \mathrm{Cu}$ solder joints during the reflow process," Journal of Electronic Packaging, vol. 140, no. 1, pp. 1-11, 2018.

[26] Y. Wen, X. Zhao, Z. Chen et al., "Reliability enhancement of $\mathrm{Sn}-1.0 \mathrm{Ag}-0.5 \mathrm{Cu}$ nano-composite solders by adding multiple sizes of $\mathrm{TiO}_{2}$ nanoparticles," Journal of Alloys and Compounds, vol. 696, pp. 799-807, 2017.

[27] M. Z. Yahaya, F. C. Ani, Z. Samsudin, S. Sahin, M. Z. Abdullah, and A. A. Mohamad, "Hardness profiles of Sn-3.0Ag$0.5 \mathrm{Cu}-\mathrm{TiO}_{2}$ composite solder by nanoindentation," Materials Science and Engineering: A, vol. 669, pp. 178-186, 2016.

[28] C. Peng, J. Shen, and H. Yin, "Influences of $\mathrm{ZrO}_{2}$ nanoparticles on the microstructures and microhardness of Sn8Zn1Bi- $\mathrm{XZrO}_{2} / \mathrm{Cu}$ solder joints," Journal of Materials Science: Materials in Electronics, vol. 24, no. 1, pp. 203-210, 2013.

[29] A. K. Gain, Y. C. Chan, and W. K. C. Yung, "Effect of additions of $\mathrm{ZrO}_{2}$ nano-particles on the microstructure and shear strength of $\mathrm{Sn}-\mathrm{Ag}-\mathrm{Cu}$ solder on $\mathrm{Au} / \mathrm{Ni}$ metallized $\mathrm{Cu}$ pads," Microelectronics Reliability, vol. 51, no. 12, pp. 2306-2313, 2011.

[30] G. Chen, H. Peng, V. V. Silberschmidt, Y. C. Chan, C. Liu, and $\mathrm{F}$. Wu, "Performance of $\mathrm{Sn}-3.0 \mathrm{Ag}-0.5 \mathrm{Cu}$ composite 
solder with TiC reinforcement: physical properties, solderability and microstructural evolution under isothermal ageing," Journal of Alloys and Compounds, vol. 685, pp. 680689, 2016.

[31] A. A. El-Daly, W. M. Desoky, T. A. Elmosalami, M. G. ElShaarawy, and A. M. Abdraboh, "Microstructural modifications and properties of $\mathrm{SiC}$ nanoparticles-reinforced Sn-3.0Ag-0.5Cu solder alloy," Materials \& Design (19802015), vol. 65, pp. 1196-1204, 2015.

[32] H. Wang, X. Hu, Q. Li, and M. Qu, "Effect of flux doped with $\mathrm{Cu}_{6} \mathrm{Sn}_{5}$ nanoparticles on the interfacial reaction of lead-free solder joints," Journal of Materials Science: Materials in Electronics, vol. 30, no. 12, pp. 11552-11562, 2019.

[33] Z. Min, Y. Qiu, X. Hu, and H. Wang, "Effect of $\mathrm{Cu}_{6} \mathrm{Sn}_{5}$ nanoparticles size on the properties of $\mathrm{Sn} 0.3 \mathrm{Ag} 0.7 \mathrm{Cu}$ nanocomposite solders and joints," Journal of Materials Science: Materials in Electronics, vol. 30, no. 15, pp. 14726-14735, 2019.

[34] X. Hu, Y. Qiu, X. Jiang, and Y. Li, "Effect of $\mathrm{Cu}_{6} \mathrm{Sn}_{5}$ nanoparticle on thermal behavior, mechanical properties and interfacial reaction of $\mathrm{Sn3} .0 \mathrm{Ag} 0.5 \mathrm{Cu}$ solder alloys," Journal of Materials Science: Materials in Electronics, vol. 29, no. 18, pp. 15983-15993, 2018.

[35] C. J. Lee, W. R. Myung, B. G. Park, and S. B. Jung, "Effect of Ag-decorated MWCNT on the mechanical and thermal property of Sn58Bi solder joints for FCLED package," Journal of Materials Science: Materials in Electronics, vol. 31, no. 13, pp. 10170-10176, 2020.

[36] H. Sun, Y. C. Chan, and F. Wu, "Effect of CNTs and Ni coated CNTs on the mechanical performance of Sn57.6Bi0.4Ag BGA solder joints," Materials Science and Engineering: A, vol. 656, pp. 249-255, 2016.

[37] Z. Zhu, Y. C. Chan, Z. Chen, C. L. Gan, and F. Wu, "Effect of the size of carbon nanotubes (CNTs) on the microstructure and mechanical strength of CNTs-doped composite $\mathrm{Sn} 0.3 \mathrm{Ag} 0.7 \mathrm{Cu}-$ CNTs solder," Materials Science and Engineering: A, vol. 727, pp. 160-169, 2018.

[38] Y. Ma, X. Li, W. Zhou, L. Yang, and P. Wu, "Reinforcement of graphene nanosheets on the microstructure and properties of Sn58Bi lead-free solder," Materials \& Design, vol. 113, pp. 264-272, 2017.

[39] A. Sharma, H. R. Sohn, and J. P. Jung, "Effect of graphene nanoplatelets on wetting, microstructure, and tensile characteristics of Sn-3.0Ag-0.5Cu (SAC) alloy," Metallurgical and Materials Transactions A, vol. 47, no. 1, pp. 494-503, 2016.

[40] X. D. Liu, Y. D. Han, H. Y. Jing, J. Wei, and L. Y. Xu, "Effect of graphene nanosheets reinforcement on the performance of Sn-Ag-Cu lead-free solder," Materials Science and Engineering: A, vol. 562, pp. 25-32, 2013.

[41] G. Chen, F. Wu, C. Liu, W. Xia, and H. Liu, "Effects of fullerenes reinforcement on the performance of $96.5 \mathrm{Sn}-3 \mathrm{Ag}-$ 0.5Cu lead-free solder," Materials Science and Engineering: A, vol. 636, pp. 484-492, 2015.

[42] G. Chen, L. Liu, J. Du et al., "Thermo-migration behavior of SAC305 lead-free solder reinforced with fullerene nanoparticles," Journal of Materials Science, vol. 51, no. 22, pp. 1007710091, 2016.

[43] G. Chen, X. Cui, Y. Wu, W. Li, and F. Wu, "Performance of 96.5Sn-3Ag-0.5Cu/fullerene composite solder under isothermal ageing and high-current stressing," Soldering \& Surface Mount Technology, 2020.
[44] J. Wang, S. Xue, C. Ma, W. Long, and S. Zhong, "Research progress on reliability of lead-free solders under special conditions," The Chinese Journal of Nonferrous Metals, vol. 28, pp. 2499-2511, 2018.

[45] G. Chen, Research on Basic Properties, Electro-and TheroMigration Performance of SAC305-x Composite Solders, Huazhong University of Science and Technology, 2016.

[46] G. Chen, F. Wu, C. Liu, V. V. Silberschmidt, and Y. C. Chan, "Microstructures and properties of new $\mathrm{Sn}-\mathrm{Ag}-\mathrm{Cu}$ lead-free solder reinforced with Ni-coated graphene nanosheets," Journal of Alloys and Compounds, vol. 656, pp. 500-509, 2016.

[47] F. Khodabakhshi, R. Sayyadi, and N. S. Javid, "Lead free Sn$\mathrm{Ag}-\mathrm{Cu}$ solders reinforced by $\mathrm{Ni}$-coated graphene nanosheets prepared by mechanical alloying: microstructural evolution and mechanical durability," Materials Science and Engineering: $A$, vol. 702, pp. 371-385, 2017.

[48] J. Shen, Y. C. Liu, and H. X. Gao, "In situ nanoparticulatereinforced lead-free $\mathrm{Sn}-\mathrm{Ag}$ composite prepared by rapid solidification," Journal of Materials Science: Materials in Electronics, vol. 18, no. 4, pp. 463-468, 2007.

[49] M. Qu, T. Cao, Y. Cui, F. Liu, and Z. Jiao, "Effect of nano$\mathrm{ZnO}$ particles on wettability, interfacial morphology and growth kinetics of $\mathrm{Sn}-3.0 \mathrm{Ag}-0.5 \mathrm{Cu}-\mathrm{xZnO}$ composite solder," Journal of Materials Science: Materials in Electronics, vol. 30, no. 21, pp. 19214-19226, 2019.

[50] M. A. A. Mohd Salleh, S. D. McDonald, Y. Terada, H. Yasuda, and K. Nogita, "Development of a microwave sintered $\mathrm{TiO}_{2}$ reinforced $\mathrm{Sn}-0.7 \mathrm{wt} \% \mathrm{Cu}-0.05 \mathrm{wt} \% \mathrm{Ni}$ alloy," Materials d Design, vol. 82, pp. 136-147, 2015.

[51] A. E. Hammad and A. A. Ibrahiem, "Enhancing the microstructure and tensile creep resistance of $\mathrm{Sn}-3.0 \mathrm{Ag}-0.5 \mathrm{Cu}$ solder alloy by reinforcing nano-sized $\mathrm{ZnO}$ particles," Microelectronics Reliability, vol. 75, pp. 187-194, 2017.

[52] G. S. Al-Ganainy, A. A. El-Daly, A. Fawzy, and N. Hussein, "Effect of adding nanometric $\mathrm{ZnO}$ particles on thermal, microstructure and tensile creep properties of Sn-6.5wt\%Zn3 wt\%In solder alloy," Journal of Materials Science: Materials in Electronics, vol. 28, no. 18, pp. 13303-13312, 2017.

[53] H. Peng, G. Chen, L. Mo, Y. C. Chan, F. Wu, and H. Liu, “An investigation on the $\mathrm{ZnO}$ retained ratio, microstructural evolution, and mechanical properties of $\mathrm{ZnO}$ doped Sn3.0Ag0.5Cu composite solder joints," Journal of Materials Science: Materials in Electronics, vol. 27, no. 9, pp. 90839093, 2016.

[54] X. Zhao, Y. Wen, Y. Li, Y. Liu, and Y. Wang, "Effect of $\gamma-\mathrm{Fe}_{2} \mathrm{O}_{3}$ nanoparticles size on the properties of Sn-1.0Ag$0.5 \mathrm{Cu}$ nano-composite solders and joints," Journal of Alloys and Compounds, vol. 662, pp. 272-282, 2016.

[55] Y. Gu, X. Zhao, Y. Li, Y. Liu, Y. Wang, and Z. Li, "Effect of nano- $\mathrm{Fe}_{2} \mathrm{O}_{3}$ additions on wettability and interfacial intermetallic growth of low- $\mathrm{Ag}$ content $\mathrm{Sn}-\mathrm{Ag}-\mathrm{Cu}$ solders on $\mathrm{Cu}$ substrates," Journal of Alloys and Compounds, vol. 627, pp. 39-47, 2015.

[56] A. Sharma, B. G. Baek, and J. P. Jung, "Influence of $\mathrm{La}_{2} \mathrm{O}_{3}$ nanoparticle additions on microstructure, wetting, and tensile characteristics of $\mathrm{Sn}-\mathrm{Ag}-\mathrm{Cu}$ alloy," Materials \& Design, vol. 87, pp. 370-379, 2015.

[57] T. Fouzder, Y. C. Chan, and D. K. Chan, "Influence of cerium oxide $\left(\mathrm{CeO}_{2}\right)$ nanoparticles on the microstructure and hardness of tin-silver-copper ( $\mathrm{Sn}-\mathrm{Ag}-\mathrm{Cu})$ solders on silver $(\mathrm{Ag})$ surface-finished copper $(\mathrm{Cu})$ substrates," Journal of Materials 
Science: Materials in Electronics, vol. 25, no. 12, pp. 53755387, 2014.

[58] S. Chellvarajoo, M. Z. Abdullah, and C. Y. Khor, "Effects of diamond nanoparticles reinforcement into lead-free $\mathrm{Sn}$ 3.0Ag- $0.5 \mathrm{Cu}$ solder pastes on microstructure and mechanical properties after reflow soldering process," Materials \& Design, vol. 82, pp. 206-215, 2015.

[59] W. R. Myung, Y. Kim, and S.-B. Jung, "Evaluation of the bondability of the epoxy-enhanced Sn-58Bi solder with ENIG and ENEPIG surface finishes," Journal of Electronic Materials, vol. 44, no. 11, pp. 4637-4645, 2015.

[60] S. M. Lee, J. W. Yoon, and S. B. Jung, "Board level drop reliability of epoxy-containing Sn-58 mass\% Bi solder joints with various surface finishes," Materials Transactions, vol. 57, no. 3, pp. 466-471, 2016.

[61] C. J. Lee, K. D. Min, H. J. Park, J. H. Kim, and S. B. Jung, "Effect of Sn-decorated MWCNTs on the mechanical reliability of Sn-58Bi solder," Electronic Materials Letters, vol. 15, no. 6, pp. 693-701, 2019.

[62] M. Zhao, L. Zhang, Z. Q. Liu, M. Y. Xiong, and L. Sun, "Structure and properties of $\mathrm{Sn}-\mathrm{Cu}$ lead-free solders in electronics packaging," Science and Technology of Advanced Materials, vol. 20, no. 1, pp. 421-444, 2019.

[63] J. Wang, S. Xue, P. Zhang, P. Zhai, and Y. Tao, "The reliability of lead-free solder joint subjected to special environment: a review," Journal of Materials Science: Materials in Electronics, vol. 30, no. 10, pp. 9065-9086, 2019.

[64] F. Wang, H. Chen, Y. Huang, L. Liu, and Z. Zhang, "Recent progress on the development of $\mathrm{Sn}-\mathrm{Bi}$ based lowtemperature $\mathrm{Pb}$-free solders," Journal of Materials Science: Materials in Electronics, vol. 30, no. 4, pp. 3222-3243, 2019.

[65] Z. H. Li, Y. Tang, Q. W. Guo, and G. Y. Li, “A diffusion model and growth kinetics of interfacial intermetallic compounds in Sn-0.3Ag-0.7Cu and Sn-0.3Ag-0.7Cu- $0.5 \mathrm{CeO}_{2}$ solder joints," Journal of Alloys and Compounds, vol. 818, article 152893, 2020.

[66] L. Zhang, W.-m. Long, and F.-j. Wang, "Microstructures, interface reaction, and properties of $\mathrm{Sn}-\mathrm{Ag}-\mathrm{Cu}$ and $\mathrm{Sn}-\mathrm{Ag}-$ $\mathrm{Cu}-0.5 \mathrm{CuZnAl}$ solders on Fe substrate," Journal of Materials Science: Materials in Electronics, vol. 31, no. 9, pp. 6645-6653, 2020.

[67] L. Yang, S. Quan, C. Liu, and H. Xiong, "Effect of Mo nanoparticles on the growth behavior of the intermetallic compounds layer in Sn3.0Ag0.5Cu/cu solder joints," Journal of Nanoscience and Nanotechnology, vol. 20, no. 4, pp. 25732577, 2020.

[68] Z. Yang, W. Zhou, and P. Wu, "Effects of Ni-coated carbon nanotubes addition on the microstructure and mechanical properties of $\mathrm{Sn}-\mathrm{Ag}-\mathrm{Cu}$ solder alloys," Materials Science and Engineering: A, vol. 590, pp. 295-300, 2014.

[69] L. Sun, L. Zhang, L. Xu, S. J. Zhong, J. Ma, and L. Bao, "Effect of nano-Al addition on properties and microstructure of lowAg content Sn-1Ag-0.5Cu solders," Journal of Materials Science: Materials in Electronics, vol. 27, no. 7, pp. 7665-7673, 2016.

[70] L. Sun, M. H. Chen, L. Zhang, L. S. Xie, and C. C. Wei, "Wettability, interfacial reaction and mechanical properties of $\mathrm{Sn} / \mathrm{Sn}-\mathrm{CuZnAl}$ solder and $\mathrm{Cu}$ sheet during solid-liquid diffusion," Journal of Materials Science: Materials in Electronics, vol. 30, no. 20, pp. 18462-18470, 2019.

[71] L. Sun, M. H. Chen, L. Zhang, and L. S. Xie, "Effect of addition of CuZnAl particle on the properties of Sn solder joint,"
Journal of Materials Processing Technology, vol. 278, article 116507, 2020.

[72] A. A. El-Daly, T. A. Elmosalami, W. M. Desoky, M. G. ElShaarawy, and A. M. Abdraboh, "Tensile deformation behavior and melting property of nano-sized $\mathrm{ZnO}$ particles reinforced $\mathrm{Sn}-3.0 \mathrm{Ag}-0.5 \mathrm{Cu}$ lead-free solder," Materials Science and Engineering: A, vol. 618, pp. 389-397, 2014.

[73] A. Fawzy, S. A. Fayek, M. Sobhy, E. Nassr, M. M. Mousa, and G. Saad, "Tensile creep characteristics of $\mathrm{Sn}-3.5 \mathrm{Ag}-0.5 \mathrm{Cu}$ (SAC355) solder reinforced with nano-metric $\mathrm{ZnO}$ particles," Materials Science and Engineering: A, vol. 603, pp. 1-10, 2014.

[74] Z. Zhao, L. Liu, H. S. Choi et al., "Effect of nano- $\mathrm{Al}_{2} \mathrm{O}_{3}$ reinforcement on the microstructure and reliability of $\mathrm{Sn}-3.0 \mathrm{Ag}-$ $0.5 \mathrm{Cu}$ solder joints," Microelectronics Reliability, vol. 60, pp. 126-134, 2016.

[75] A. K. Gain, L. Zhang, and Y. C. Chan, "Microstructure, elastic modulus and shear strength of alumina $\left(\mathrm{Al}_{2} \mathrm{O}_{3}\right)$ nanoparticles-doped tin-silver-copper $(\mathrm{Sn}-\mathrm{Ag}-\mathrm{Cu})$ solders on copper $(\mathrm{Cu})$ and gold/nickel $(\mathrm{Au} / \mathrm{Ni})$-plated $\mathrm{Cu}$ substrates," Journal of Materials Science: Materials in Electronics, vol. 26, no. 9, pp. 7039-7048, 2015.

[76] J. Wu, S. Xue, J. Wang, and M. Wu, "Coupling effects of rareearth $\mathrm{Pr}$ and $\mathrm{Al}_{2} \mathrm{O}_{3}$ nanoparticles on the microstructure and properties of $\mathrm{Sn}-0.3 \mathrm{Ag}-0.7 \mathrm{Cu}$ low-Ag solder," Journal of Alloys and Compounds, vol. 784, pp. 471-487, 2019.

[77] Y. Tang, G. Y. Li, D. Q. Chen, and Y. C. Pan, "Influence of $\mathrm{TiO}_{2}$ nanoparticles on IMC growth in $\mathrm{Sn}-3.0 \mathrm{Ag}-0.5 \mathrm{Cu}-$ $\mathrm{xTiO}_{2}$ solder joints during isothermal aging process," Journal of Materials Science: Materials in Electronics, vol. 25, no. 2, pp. 981-991, 2014.

[78] Y. Tang, S. M. Luo, K. Q. Wang, and G. Y. Li, "Effect of Nano$\mathrm{TiO}_{2}$ particles on growth of interfacial $\mathrm{Cu}_{6} \mathrm{Sn}_{5}$ and $\mathrm{Cu}_{3} \mathrm{Sn}$ layers in $\mathrm{Sn}-3.0 \mathrm{Ag}-0.5 \mathrm{Cu}-\mathrm{xTiO}_{2}$ solder joints," Journal of Alloys and Compounds, vol. 684, pp. 299-309, 2016.

[79] L. C. Tsao, "Suppressing effect of $0.5 \mathrm{wt} . \%$ nano- $\mathrm{TiO}_{2}$ addition into $\mathrm{Sn}-3.5 \mathrm{Ag}-0.5 \mathrm{Cu}$ solder alloy on the intermetallic growth with $\mathrm{Cu}$ substrate during isothermal aging," Journal of Alloys and Compounds, vol. 509, no. 33, pp. 8441-8448, 2011.

[80] T. Fouzder, I. Shafiq, Y. C. Chan, A. Sharif, and W. K. C. Yung, "Influence of $\mathrm{SrTiO}_{3}$ nano-particles on the microstructure and shear strength of $\mathrm{Sn}-\mathrm{Ag}-\mathrm{Cu}$ solder on $\mathrm{Au} / \mathrm{Ni}$ metallized Cu pads," Journal of Alloys and Compounds, vol. 509, no. 5, pp. 1885-1892, 2011.

[81] G. Chen, X. Cui, Y. Wu, W. Li, and F. Wu, "Microstructural, compositional and hardness evolutions of $96.5 \mathrm{Sn}-3 \mathrm{Ag}-$ $0.5 \mathrm{Cu} / \mathrm{TiC}$ composite solder under thermo-migration stressing," Journal of Materials Science: Materials in Electronics, vol. 31, no. 12, pp. 9492-9503, 2020.

[82] G. Ban, F. Sun, Y. Liu, and S. Cong, "Effect of nano-Cu addition on microstructure evolution of $\mathrm{Sn} 0.7 \mathrm{Ag} 0.5 \mathrm{Cu}-\mathrm{BiNi} / \mathrm{Cu}$ solder joint," Soldering \& Surface Mount Technology, vol. 29, no. 2, pp. 92-98, 2017.

[83] Y. Huang, Z. Xiu, G. Wu, Y. Tian, and P. He, "Sn-3.0Ag$0.5 \mathrm{Cu}$ nanocomposite solders reinforced by graphene nanosheets," Journal of Materials Science: Materials in Electronics, vol. 27, no. 7, pp. 6809-6815, 2016.

[84] L. Xu, X. Chen, H. Jing, L. Wang, J. Wei, and Y. Han, "Design and performance of Ag nanoparticle-modified graphene/SnAgCu lead-free solders," Materials Science and Engineering: A, vol. 667, pp. 87-96, 2016. 
[85] K. M. Kumar, V. Kripesh, L. Shen, and A. A. O. Tay, "Study on the microstructure and mechanical properties of a novel SWCNT-reinforced solder alloy for ultra-fine pitch applications," Thin Solid Films, vol. 504, no. 1-2, pp. 371-378, 2006.

[86] K. M. Kumar, V. Kripesh, and A. A. O. Tay, "Single-wall carbon nanotube (SWCNT) functionalized $\mathrm{Sn}-\mathrm{Ag}-\mathrm{Cu}$ lead-free composite solders," Journal of Alloys and Compounds, vol. 450, no. 1-2, pp. 229-237, 2008.

[87] M. I. I. Ramli, M. A. A. Mohd Salleh, H. Yasuda, J. Chaiprapa, and K. Nogita, "The effect of Bi on the microstructure, electri$\mathrm{cal}$, wettability and mechanical properties of $\mathrm{Sn}-0.7 \mathrm{Cu}-$ $0.05 \mathrm{Ni}$ alloys for high strength soldering," Materials \& Design, vol. 186, p. 108281, 2020.

[88] J. Fan, H. Zhai, Z. Liu et al., "Microstructure evolution, thermal and mechanical property of Co alloyed Sn-0.7Cu leadfree solder," Journal of Electronic Materials, vol. 49, no. 4, pp. 2660-2668, 2020.

[89] A. M. El-Taher, S. E. Abd El Azeem, and A. A. Ibrahiem, "Influence of permanent magnet stirring on dendrite morphological and elastic properties of a novel $\mathrm{Sn}-\mathrm{Ag}-\mathrm{Cu}-\mathrm{Sb}-$ Al solder alloy by ultrasonic pulse echo method," Journal of Materials Science: Materials in Electronics, vol. 31, no. 12, pp. 9630-9640, 2020.

[90] M. Zhao, L. Zhang, Z. Q. Liu et al., "Microstructures and properties of $\mathrm{SnAgCu}$ lead-free solders bearing CuZnAl particles," Journal of Materials Science: Materials in Electronics, vol. 30, no. 16, pp. 15054-15063, 2019.

[91] F. Wang, Y. Ding, L. Liu, Y. Huang, and M. Wu, "Wettability, interfacial behavior and joint properties of Sn-15Bi solder," Journal of Electronic Materials, vol. 48, no. 10, pp. 68356848, 2019.

[92] P. Zhang, S. Xue, J. Wang, P. Xue, S. Zhong, and W. Long, "Effect of nanoparticles addition on the microstructure and properties of lead-free solders: a review," Applied Sciences, vol. 9, no. 10, p. 2044, 2019.

[93] A. Ting Tan, A. Wen Tan, and F. Yusof, "Influence of nanoparticle addition on the formation and growth of intermetallic compounds (IMCs) in $\mathrm{Cu} / \mathrm{Sn}-\mathrm{Ag}-\mathrm{Cu} / \mathrm{Cu}$ solder joint during different thermal conditions," Science and Technology of Advanced Materials, vol. 16, no. 3, article 033505, 2016.

[94] A. Sharma, A. K. Srivastava, K. Lee, and B. Ahn, "Impact of non-reactive ceria nanoparticles on the wettability and reaction kinetics between lead-free $\mathrm{Sn}-58 \mathrm{Bi}$ and $\mathrm{Cu}$ pad," Metals and Materials International, vol. 25, no. 4, pp. 1027-1038, 2019.

[95] A. K. Gain and L. Zhang, "Interfacial microstructure, wettability and material properties of nickel $(\mathrm{Ni})$ nanoparticle doped tin-bismuth-silver ( $\mathrm{Sn}-\mathrm{Bi}-\mathrm{Ag})$ solder on copper $(\mathrm{Cu})$ substrate," Journal of Materials Science: Materials in Electronics, vol. 27, no. 4, pp. 3982-3994, 2016.

[96] S. Ismathullakhan, H. Lau, and Y.-c. Chan, "Enhanced electromigration reliability via $\mathrm{Ag}$ nanoparticles modified eutectic Sn-58Bi solder joint," Microsystem Technologies, vol. 19, no. 7, pp. 1069-1080, 2013.

[97] N. Jiang, L. Zhang, Z. Q. Liu et al., "Influences of doping Ti nanoparticles on microstructure and properties of Sn58Bi solder," Journal of Materials Science: Materials in Electronics, vol. 30, no. 19, pp. 17583-17590, 2019.

[98] X. Li, Y. Ma, W. Zhou, and P. Wu, "Effects of nanoscale $\mathrm{Cu}_{6}$ $\mathrm{Sn}_{5}$ particles addition on microstructure and properties of SnBi solder alloys," Materials Science and Engineering: A, vol. 684, pp. 328-334, 2017.
[99] Y. Liu, H. Zhang, and F. Sun, "Solderability of SnBi-nano Cu solder pastes and microstructure of the solder joints," Journal of Materials Science: Materials in Electronics, vol. 27, no. 3, pp. 2235-2241, 2016.

[100] H. Sun, Q. Li, and Y. C. Chan, "A study of Ag additive methods by comparing mechanical properties between Sn57.6Bi0.4Ag and 0.4 wt\% nano-Ag-doped Sn58Bi BGA solder joints," Journal of Materials Science: Materials in Electronics, vol. 25, no. 10, pp. 4380-4390, 2014.

[101] L. Zhang and Z. Q. Liu, "Inhibition of intermetallic compounds growth at $\mathrm{Sn}-58 \mathrm{Bi} / \mathrm{Cu}$ interface bearing $\mathrm{CuZnAl}$ memory particles $(2-6 \mu \mathrm{m})$," Journal of Materials Science: Materials in Electronics, vol. 31, no. 3, pp. 2466-2480, 2020.

[102] T. Hu, Y. Li, Y. C. Chan, and F. Wu, "Effect of nano $\mathrm{Al}_{2} \mathrm{O}_{3}$ particles doping on electromigration and mechanical properties of Sn-58Bi solder joints," Microelectronics Reliability, vol. 55, no. 8, pp. 1226-1233, 2015.

[103] L. Yang, W. Zhou, Y. Liang, W. Cui, and P. Wu, "Improved microstructure and mechanical properties for Sn58Bi solder alloy by addition of $\mathrm{Ni}$-coated carbon nanotubes," Materials Science and Engineering: A, vol. 642, pp. 7-15, 2015.

[104] M. M. Billah and Q. Chen, "Strength of MWCNT-reinforced 70Sn-30Bi solder alloys," Journal of Electronic Materials, vol. 45, no. 1, pp. 98-103, 2016.

[105] D. Ma and P. Wu, "Improved microstructure and mechanical properties for $\mathrm{Sn} 58 \mathrm{Bi} 0.7 \mathrm{Zn}$ solder joint by addition of graphene nanosheets," Journal of Alloys and Compounds, vol. 671, pp. 127-136, 2016.

[106] L. Yang, C. Du, J. Dai, N. Zhang, and Y. Jing, "Effect of nanosized graphite on properties of Sn-Bi solder," Journal of Materials Science: Materials in Electronics, vol. 24, no. 11, pp. 4180-4185, 2013.

[107] L. Yang, J. Ge, Y. Zhang, J. Dai, and Y. Jing, "Electromigration reliability for $\mathrm{Al}_{2} \mathrm{O}_{3}$-reinforced $\mathrm{Cu} / \mathrm{Sn}-58 \mathrm{Bi} / \mathrm{Cu}$ composite solder joints," Journal of Materials Science: Materials in Electronics, vol. 28, no. 3, pp. 3004-3012, 2017.

[108] P. He, X. C. Lü, T.-s. Lin et al., "Improvement of mechanical properties of $\mathrm{Sn}-58 \mathrm{Bi}$ alloy with multi-walled carbon nanotubes," Transactions of Nonferrous Metals Society of China, vol. 22, pp. s692-s696, 2012.

[109] Y. H. Ko, J. D. Lee, T. Yoon, C. W. Lee, and T. S. Kim, “Controlling interfacial reactions and intermetallic compound growth at the interface of a lead-free solder joint with layerby-layer transferred graphene," ACS Applied Materials \& Interfaces, vol. 8, no. 8, pp. 5679-5686, 2016.

[110] M. A. A. Mohd Salleh, S. D. McDonald, C. M. Gourlay, H. Yasuda, and K. Nogita, "Suppression of $\mathrm{Cu}_{6 \mathrm{Sn}}{ }_{5}$ in ${ }_{\mathrm{TiO}} 2$ reinforced solder joints after multiple reflow cycles," Materials \& Design, vol. 108, pp. 418-428, 2016.

[111] M. A. A. Mohd Salleh, S. D. McDonald, and K. Nogita, "Effects of $\mathrm{Ni}$ and $\mathrm{TiO}_{2}$ additions in as-reflowed and annealed $\mathrm{Sn} 0.7 \mathrm{Cu}$ solders on Cu substrates," Journal of Materials Processing Technology, vol. 242, pp. 235-245, 2017.

[112] M. A. A. Mohd Salleh, A. M. M. A. Bakri, M. H. Zan, F. Somidin, N. F. Mohd Alui, and Z. A. Ahmad, "Mechanical properties of $\mathrm{Sn}-0.7 \mathrm{Cu} / \mathrm{Si}_{3} \mathrm{~N}_{4}$ lead-free composite solder," Materials Science and Engineering: A, vol. 556, pp. 633-637, 2012.

[113] M. E. Alam, S. M. L. Nai, and M. Gupta, "Development of high strength $\mathrm{Sn}-\mathrm{Cu}$ solder using copper particles at nanolength scale," Journal of Alloys and Compounds, vol. 476, no. 1-2, pp. 199-206, 2009. 
[114] T. Fouzder, Q. Li, Y. C. Chan, and D. K. Chan, "Microstructure and kinetic analysis of the properties and behavior of nickel (Ni) nano-particle doped tin-zinc-bismuth (Sn$8 \mathrm{Zn}-3 \mathrm{Bi}$ ) solders on immersion silver (Ag)-plated copper $(\mathrm{Cu})$ substrates," Journal of Materials Science: Materials in Electronics, vol. 25, no. 6, pp. 2529-2539, 2014.

[115] A. K. Gain, Y. C. Chan, and W. K. C. Yung, "Effect of nano Ni additions on the structure and properties of Sn-9Zn and Sn$\mathrm{Zn}-3 \mathrm{Bi}$ solders in $\mathrm{Au} / \mathrm{Ni} / \mathrm{Cu}$ ball grid array packages," Materials Science and Engineering: B, vol. 162, no. 2, pp. 92-98, 2009.

[116] A. K. Gain and L. Zhang, "Microstructure, thermal analysis and damping properties of $\mathrm{Ag}$ and $\mathrm{Ni}$ nano-particles doped Sn-8Zn-3Bi solder on OSP-Cu substrate," Journal of Alloys and Compounds, vol. 617, pp. 779-786, 2014.

[117] W. Q. Xing, X. Y. Yu, H. Li et al., "Microstructure and mechanical properties of Sn-9Zn-xAl 2 O 3 nanoparticles $(\mathrm{x}=0-1)$ lead-free solder alloy: first-principles calculation and experimental research," Materials Science and Engineering: A, vol. 678, pp. 252-259, 2016.

[118] L. C. Tsao, C. H. Huang, C. H. Chung, and R. S. Chen, "Influence of $\mathrm{TiO}_{2}$ nanoparticles addition on the microstructural and mechanical properties of $5 n 0.7 \mathrm{Cu}$ nano-composite solder," Materials Science and Engineering: A, vol. 545, pp. 194-200, 2012. 